\title{
Loss of MMP-8 in ductal carcinoma in situ (DCIS)-associated myoepithelial cells contributes to tumour promotion through altered adhesive and proteolytic function
}

Muge Sarper ${ }^{1 \dagger}$, Michael D. Allen ${ }^{2^{*}+}$ (D) Jenny Gomm², Linda Haywood ${ }^{2}$, Julie Decock ${ }^{3}$, Sally Thirkettle ${ }^{2}$, Ahsen Ustaoglu², Shah-Jalal Sarker ${ }^{4}$, John Marshall2, Dylan R. Edwards ${ }^{5}$ and J. Louise Jones ${ }^{2^{*}}$

\begin{abstract}
Background: Normal myoepithelial cells (MECs) play an important tumour-suppressor role in the breast but display an altered phenotype in ductal carcinoma in situ (DCIS), gaining tumour-promoter functions. Matrix metalloproteinase-8 (MMP-8) is expressed by normal MECs but is lost in DCIS. This study investigated the function of MMP-8 in MECs and the impact of its loss in DCIS.
\end{abstract}

Methods: Primary normal and DCIS-associated MECs, and normal (N-1089) and DCIS-modified myoepithelial (B6-1089) cell lines, were used to assess MMP-8 expression and function. $\beta 6-1089$ lacking MMP-8 were transfected with MMP-8 WT and catalytically inactive MMP-8 EA, and MMP-8 in N-1089 MEC was knocked down with siRNA. The effect on adhesion and migration to extracellular matrix (ECM), localisation of a6 $\beta 4$ integrin to hemidesmosomes (HD), TGF- $\beta$ signalling and gelatinase activity was measured. The effect of altering MEC MMP-8 expression on tumour cell invasion was investigated in 2D and 3D organotypic models.

Results: Assessment of primary cells and MEC lines confirmed expression of MMP-8 in normal MEC and its loss in DCIS-MEC. Over-expression of MMP-8 WT but not MMP-8 EA in $\beta 6-1089$ cells increased adhesion to ECM proteins and reduced migration. Conversely, knock-down of MMP-8 in N-1089 reduced adhesion and increased migration. Expression of MMP-8 WT in $\beta 6-1089$ led to greater localisation of a6ß4 to HD and reduced retraction fibre formation, this being reversed by MMP-8 knock-down in N-1089. Over-expression of MMP-8 WT reduced TGF- $\beta$ signalling and gelatinolytic activity. MMP-8 knock-down enhanced TGF- $\beta$ signalling and gelatinolytic activity, which was reversed by blocking MMP-9 by knock-down or an inhibitor. MMP-8 WT but not MMP-8 EA over-expression in $\beta 6-1089$ reduced breast cancer cell invasion in 2D and 3D invasion assays, while MMP-8 knock-down in N-1089 enhanced cancer cell invasion. Staining of breast cancer cases for MMP-8 revealed a statistically significant loss of MMP-8 expression in DCIS with invasion versus pure DCIS ( $p=0.001)$.

Conclusions: These data indicate MMP-8 is a vital component of the myoepithelial tumour-suppressor function. It restores MEC interaction with the matrix, opposes TGF- $\beta$ signalling and MMP-9 proteolysis, which contributes to inhibition of tumour cell invasion. Assessment of MMP-8 expression may help to determine risk of DCIS progression.

Keywords: Ductal carcinoma in situ, Myoepithelial cell, Microenvironment, MMP-8, Adhesion, Hemidesmosomes, Organotypic assays, Invasion

\footnotetext{
* Correspondence: m.allen@qmul.ac.uk; I.j.jones@qmul.ac.uk

${ }^{\dagger}$ Equal contributors

${ }^{2}$ Centre for Tumour Biology, Barts Cancer Institute, John Vane Science Centre,

Charterhouse Square, Queen Mary University of London, Charterhouse

Square, London EC1M 6BQ, UK

Full list of author information is available at the end of the article
} 


\section{Background}

Many invasive breast cancers (IBC) develop through a pre-invasive stage known as ductal carcinoma in situ (DCIS) where the proliferative neoplastic cells are retained within the breast duct surrounded by an intact myoepithelial cell (MEC) layer lying in contact with basement membrane [1]. DCIS is a non-obligatory precursor of IBC; only around half of untreated cases progress to IBC, when the tumour cells breach the MEC-basement membrane barrier [2, 3]. However, the molecular mechanisms underlying the transition of DCIS to IBC are poorly understood, and identifying those cases that will progress and those that will not remains a major challenge $[4,5]$.

Molecular profiling studies demonstrate that DCIS tumour cells and their invasive counterparts share a similar signature and DCIS is as genetically advanced as established invasive disease $[6,7]$. Therefore, in order to understand the changes that trigger invasion, attention has focused on the role of the microenvironment [8-11]. MECs are a unique component of the microenvironment in the breast. In normal breast ducts, MECs adhere tightly to the basement membrane using prominent hemidesmosome (HD) formation [12]. They show a high level of expression of anti-tumourigenic factors, such as proteinase inhibitors and anti-angiogenic mediators, and in vitro studies have demonstrated broad tumour-suppressor activities of normal primary MEC and MEC lines [13-15]. In DCIS, the MECs become altered, showing changes in gene expression, epigenetics and phenotype [13, 14, 16, 17], though the functional significance of these changes has not been established [9, 18-20].

A previous study has indicated that in normal ducts MECs appear to be the main source of matrix metalloproteinase-8 (MMP-8), which is a major collagenase that cleaves Collagen type- I (Col -I) [21]. Expression of MMP-8 appears to be lost in DCISassociated MECs [22]. MMPs are a large family of endopeptidases, which have the ability to remodel extracellular matrix (ECM) and are upregulated in many cancers, such that the MMP family is conventionally regarded as consisting of key enzymes that contribute to the process of cancer cell invasion and metastasis [3, 23-25]. However, the failure of broad range MMP inhibitors in anticancer trials suggests an incomplete understanding of the complex function of this family; specifically when and how they act in cancer [3, 23-25]. Moreover; regulatory interactions (compensation or inhibition) between MMP family members construct a complex web through which the expression and activity of MMPs are constantly controlled $[25,26]$. One particular example is MMP-9, which is implicated in the acquisition of DCIS-associated phenotype in MECs [27] at the same stage when MECs lose MMP-8 expression. Since it was first reported that $\mathrm{MMP}-8^{-/-}$mice exhibit increased incidence of skin tumours when challenged with chemical carcinogenesis, MMP-8 has been demonstrated to exert a clear tumour-suppressor function $[22,26,28,29]$. There is a growing body of evidence accumulating that MMP-8 has an anticancer role in breast cancer, malignant melanoma and tongue squamous cell carcinoma, [22, 26, 28, 30-32]. Interestingly, identification of non-structural substrates of MMP-8 [28, 33-37], suggests that the biological function of MMP-8 is much more complicated than just Col-I degradation.

The biological significance of loss of MEC-derived MMP-8 on MEC phenotype and MEC-breast cancer cell crosstalk remains elusive, especially whether MMP-8 may contribute to the tumour-suppressor function of MECs. In this study we employed 2D and $3 \mathrm{D}$ in vitro models to recapitulate the DCIS tumour microenvironment in order to investigate how MMP-8 is involved in MEC-breast cancer cell communication, and whether loss of MMP- 8 contributes to loss of tumour-suppressor activity and promotes progression to invasive disease. Improving our understanding of the factors that contribute to transition of DCIS to invasion will aid in the future development of predictive signatures to help stratify patient management more appropriately, and avoid the 'overtreatment' that has caused such controversy in the breast screening programme.

\section{Methods}

\section{Immunohistochemistry}

Breast tissue samples were obtained from surgical specimens from patients undergoing breast surgery at Barts Health NHS Trust London. The study was performed following patient consent and approval from the local research ethics committee (reference: 05/Q0403/199 and 09/H075/39). Seven were normal breast cases from reduction mammoplasty, nine were cases of DCIS (high, intermediate and low grade) and nine were cases of DCIS with concomitant invasion.

Sections were dewaxed in xylene and antigen retrieved in citrate buffer pH6; followed by incubation with MMP-8 rabbit polyclonal antibody (Atlas, Cambridge, MA, USA, HPA02122, 1:750). Sections subsequently were incubated with goat anti-rabbit biotinylated $F\left(a b^{\prime}\right) 2$ for $30 \mathrm{~min}$, developed using $\mathrm{ABC}$ reagent and superDAB (Dako, Glostrup, Denmark) then counterstained with hematoxylin [7].

\section{Cell lines and cell culture}

All breast cancer cell lines were obtained from American Type Culture Collection (ATCC) and verified with STR profiling (LGC Standards, Teddington, UK, tracking number 710081047). MCF-7 and MDA-MB-231 cells were cultured in $10 \%$ fetal bovine serum (FBS, PAA Laboratories, Pasching, Austria, A15-14) containing (complete) DMEM 
(PAA Laboratories, E15-843). SUM159 cells were grown in complete Ham's F12 (PAA Laboratories, E15-817) with hydrocortisone (Sigma-Aldrich, St. Louis, MO, USA, HO $888,1 \mu \mathrm{g} / \mathrm{ml}$ ) and insulin (Sigma-Aldrich, I9278, $1 \mu \mathrm{g} / \mathrm{ml}$ ).

\section{Generation of myoepithelial cell lines}

The h-TERT/SV40 LgT immortalised MEC line was a gift from M. O'Hare and P. Jat, Institute of Neurology, UCL, London. $\alpha v \beta 6$ integrin over-expressing and control (normal) MEC line was generated as previously described [27], and termed $\beta 6-1089$ and N-1089 respectively. These cells were cultured in the presence of hydrocortisone $(1 \mu \mathrm{g} / \mathrm{ml})$, epidermal growth factor (EGF, Sigma-Aldrich, 9644, $10 \mathrm{ng} / \mathrm{ml})$, insulin $(1 \mu \mathrm{g} / \mathrm{ml})$ and puromycin $(1 \mu \mathrm{g} / \mathrm{ml}$, Sigma-Aldrich) in Ham's F12.

\section{Isolation of primary myoepithelial and luminal epithelial populations from normal breast and DCIS tissue}

Primary cell isolation protocol was adapted from Gomm et al. [38]. In brief, reduction mammoplasty tissue or DCIS tissue was digested overnight at $37^{\circ} \mathrm{C}$ with $1 \mathrm{mg} / \mathrm{ml}$ collagenase (Sigma-Aldrich, C2674) and hyaluronidase (Sigma-Aldrich, H3506) on a roller-mixer. Following washing and a sedimentation step the organoids were further digested with trypsin/EDTA (PAA Laboratories, L11004) and DNase (Roche Diagnostics, Basel, Switzerland, 10104159001) then filtered through a $40-\mu \mathrm{m}$ filter (Becton Dickinson, Franklin Lakes, NJ, USA). Cells were incubated in a 1:1 ratio sequentially with magnetic beads (Dynal Biotech., Milwaukee, WI, USA) coated with common acute lymphoblastic leukemia antigen (CALLA) antibody (AbD Serotech, Oxford, UK, MCA1556) to isolate normal MECs or anti- $\beta 4$ integrin antibody (EMD Millipore, Billerica, MA, USA, mAB 1964) for DCIS myoepithelial cells. This was followed by epithelial cell adhesion molecule (EpCAM) antibody-coated epithelial-enriched magnetic beads (Invitrogen, Carlsbad, CA, USA, 161.02) to isolate luminal epithelial cells (LECs). Primary fibroblasts were grown from the media produced by the sedimentation step. The purity of these populations has been verified by staining for CK8, CK18, EMA for the luminal epithelial cells and CK14, SMA, CD10, vimentin, p63 for the myoepithelial cells, as described in previous publications $[27,38]$.

\section{MMP-8 over-expression}

The wild-type MMP-8 (WT) and inactive mutant MMP8 (EA) coding inserts cloned into pcDNA4 (EcoRI and XhoI restriction sites, Invitrogen, K103002) have been described previously [39]. Empty pcDNA4 vector was used as a control.

B6-1089 cells were plated at a density $7 \times 10^{4}$ cells per well onto 6 -well plates 24 hours prior to transfection. $\beta 6$ 1089 cells were transfected with $1 \mu \mathrm{g}$ DNA per well with Genejuice reagent (Novagen, Merck KGaA, Darmstadt,
Germany, 70967) according to the manufacturer's instructions for 5 hours at $37^{\circ} \mathrm{C}$. All functional experiments were performed 24 hours after transfection. For generation of conditioned media $(\mathrm{CM})$, complete media was replaced with serum-free media (SFM) and harvested after 24 hours, followed by centrifugation at $1200 \mathrm{rpm}$ for $3 \mathrm{mi}-$ nutes to remove cell debris and storage at $-80{ }^{\circ} \mathrm{C}$.

\section{MMP-8 knock-down}

$\mathrm{N}-1089$ cells were seeded onto six-well plates at a density $7 \times 10^{4}$ cells per well and incubated for 24 hours at $37{ }^{\circ} \mathrm{C}$, after which media was replenished and N-1089 cells were transfected with $5 \mathrm{nM}$ pooled MMP-8 siRNA (Thermo Fisher Scientific, Waltham, MA, USA, MU005969-00-0020) or Luciferase GL3 Duplex control siRNA (siLUC, Thermo Fisher Scientific, D-001400-01-20) [40] using interferin transfection reagent (Polyplus tranfection, Peqlab Biotechnologie GmbH, Erlangen, Germany, 409-01) according to the manufacturer's instructions. All functional assays were carried out 96 hours after transfection. To generate CM, cells were serum starved for 24 hours and media was harvested as described above.

\section{Reverse transcription and q-PCR}

RNA was extracted with RNeasy kit (Qiagen, Hilden, Germany, 74104) and reverse transcribed with Superscript II (Invitrogen, 11064-014). One hundred nanograms of cDNA were used per reaction.

All primers made up at $100 \mathrm{mM}$ stock concentration and used at $0.4 \mathrm{mM}$ final concentration. Reactions were performed using Immomix Red Master Mix (Bioline, London, UK, Bio 25-022) in a total reaction volume of $25 \mu \mathrm{l}$. For nested PCR, $2 \mu \mathrm{l} \mathrm{PCR} \mathrm{product} \mathrm{was} \mathrm{used} \mathrm{as} \mathrm{a}$ template for second-round PCR. The products were separated on a $1 \%$ agarose (Invitrogen, 16500-500) gel for $45 \mathrm{~min}$ at $100 \mathrm{v}$ and visualised under UV light (AutoChemi System, UVP, Cambridge, UK).

Q-PCR was carried out using SYBR Green (Applied Biosystems, Foster City, CA, USA, 4367659) chemistry. One hundred nanograms of cDNA input was used per reaction. Primers were used at $0.3 \mathrm{mM}$ final concentration in $10 \mu \mathrm{l}$ total PCR volume for one well of a 96-well plate. Reactions were carried out on a Step One Plus instrument (Applied Biosystems).

Primer sequences - MMP-8 forward: 5'-GCCGAAG AAACATGGACCAAC-3', MMP-8 nested forward: 5' ACTCCTCTGACCCTGGTGCC-3', MMP-8 reverse: 5' - TGAGGATGCCTTCTCCAGAAG-3', $\alpha v \beta 6$ forward: 5' - GAAGGAATGATCACGTACAAG-3', $\alpha v \beta 6$ reverse: 5' - AGCAGGGAGTCTTCACAGGT-3', 18 s forward: 5' -CACGGGAAACCTCACCCGGC-3', 18 s reverse: 5' AGCAGGGAGTCTTCACAGGT-3'. 


\section{Western blotting}

Cells were lysed with radioimmunoprecipitation (RIPA) buffer. CM from N-1089 and B6-1089 cells was concentrated 20× using centrifugal units (EMD Millipore, 4FC 800324) with $3 \mathrm{~K}$ molecular weight cutoff (MWCO) at $4000 \mathrm{~g}$ for 45 minutes at $4{ }^{\circ} \mathrm{C}$. Samples were boiled in reducing ( $\beta$-mercaptoethanol containing) laemmli buffer for 5 minutes at $95{ }^{\circ} \mathrm{C}$, then separated with SDS (National Diagnostics, Atlanta, GA, USA, EC874) acrylamide (National Diagnostics, EC890) gel for 90 minutes at $125 \mathrm{~V}$ at room temperature. Recombinant human MMP-8 western blot standard (R\&D Systems, Minneapolis, MN, USA, WBC017) was loaded as positive control. The gel was transferred to a nitrocellulose membrane (Hybon C extra, RPN203E) for 90 minutes at $30 \mathrm{~V}$ at room temperature and Western blotting was performed as previously described [27].

Primary antibodies used included mouse anti-human MMP-8 antibody (R\&D Systems, mAb 908), SMAD2 (Cell Signaling Technology, Danvers, MA, USA, 3122), pSMAD2 (Cell Signaling Technology, 3101). Protein loading was confirmed with HSC70 (Santa Cruz Biotechnology, Dallas, TX, USA, sc-7298) or actin (Santa Cruz Biotechnology, sc-1615) as loading controls. For MMP-8 over-expressed samples, the membrane was probed with anti-V5 antibody (Invitrogen, R960-25). Depending on the primary antibody species, horseradish peroxidase (HRP)conjugated mouse secondary (Dako, P0447), rabbit secondary (Dako, P0448) or goat secondary (Dako; P0160) antibody was used. The membrane was developed with ECL (GE Healthcare, Chicago, IL, USA, RPN 2106) and densitometric quantification analysis was performed with Image J software (National Institutes of Health, Bethesda, MD, USA).

\section{Invasion assays}

Boyden chamber transwells (Corning, Corning, NY, USA, 3422, pore size: $8 \mu \mathrm{m}$ ) coated with $70 \mu$ liluted Matrigel (1 volume Matrigel: 2 volumes ice-cold serumfree media) were used to measure in vitro invasive capacity, as previously described [27]. $2 \times 10^{4}$ modified 36-1089 or N-1089 cells were plated in serum-free media in the lower chamber. $3 \times 10^{4} \mathrm{MCF}-7$, MDA-MB231or SUM159 breast cancer cells were seeded onto the Matrigel-coated insert. Invasion assays were carried out at $37{ }^{\circ} \mathrm{C}$ over 24 hours, or 48 hours for MCF-7 cells. Invaded cells were harvested with $10 \times$ trypsin/EDTA (PAA Laboratories, L11-003) from the underside of the transwell and counted with a CASY counter (Schärfe System, Reutlingen, Germany).

\section{Viability assay}

To analyse MEC viability, $3 \times 10^{4} \beta 6-1089$ or N-1089 cells were seeded onto a 24-well plate and incubated for
24 hours at $37^{\circ} \mathrm{C}$ after which the media was replenished and MTS reagent (Promega, Madison, WI, USA, cell titer 96 Aqueous, G5421) was added (5:1 media:MTS v/v ratio) then incubated for 1 hour at $37{ }^{\circ} \mathrm{C}$. The MTS containing mixed media was then collected and placed on a 96-well plate and read at $495 \mathrm{~nm}$ (Tecan, Männedorf, Switzerland, infiniteF50).

To analyse breast cancer cell viability $3 \times 10^{4} \mathrm{MCF}-7$, MDA-MB-231 or SUM159 cells were incubated with CM collected from modified 36-1089 or N-1089 cells for 24 hours. Viability was quantified using MTS reagent as described above.

\section{Adhesion assays}

Non-tissue culture-treated 96-well plates were coated with $100 \mu \mathrm{l}$ of the following matrices in triplicate at given concentrations: Fibronectin at $1 \mu \mathrm{g} / \mathrm{ml}$, rat tail Collagen-I (BD Biosciences, Franklin Lakes, NJ, USA, 354236) at $0.5 \mu \mathrm{g} / \mathrm{ml}$, Matrigel at $0.5 \mu \mathrm{g} / \mathrm{ml}$, Tenascin-C (EMD Millipore, CC 065) at $3 \mu \mathrm{g} / \mathrm{ml}$, Laminin-I at 10 $\mu \mathrm{g} / \mathrm{ml}$, Collagen-IV at $10 \mu \mathrm{g} / \mathrm{ml}$ and latency-associated peptide (LAP) (Sigma-Aldrich, L3408) at $0.5 \mu \mathrm{g} / \mathrm{ml}$. Three wells of each plate were coated with $0.1 \%$ bovine serum albumin (BSA, PAA Laboratories, K45-001) in phosphate-buffered saline (PBS) (w/v) as a control. Coated plates were incubated for 1 hour at $37{ }^{\circ} \mathrm{C}$ after which wells were washed twice with $100 \mu \mathrm{l}$ PBS per well.

Modified $36-1089$ or N-1089 cells were serum starved for 24 hours prior to the experiment. $3 \times 10^{3}$ cells were seeded in $100 \mu \mathrm{l}$ of serum-free Ham's F12 per well and allowed to adhere for 1 hour at $37{ }^{\circ} \mathrm{C}$. Then $0.25 \mu \mathrm{l}$ of Calcein AM (Invitrogen, C1430) cell tracker was added and incubated for 15 minutes at $37{ }^{\circ} \mathrm{C}$ after which the plate was washed twice with $100 \mu \mathrm{l}$ PBS per well, and $100 \mu \mathrm{l}$ of SFM was added. The plate was read at 490/520 $\mathrm{nm}$ on a fluorescent reader (BMG Labtech, Aylesbury, UK, FLUOstar Optima). The adhesion was calculated as the fluorescence value of adherent cells and normalised to that of control cells.

\section{Migration assays}

The underside of Boyden chamber transwells were coated with $100 \mu \mathrm{l}$ of ECM or $0.1 \%$ BSA in PBS as a control, and incubated for 1 hour at room temperature. ECM components and concentrations were as for the adhesion assays. Following incubation the underside of the transwell was washed with $100 \mu \mathrm{l}$ PBS and placed into $500 \mu \mathrm{l}$ of SFM containing well of a 24 -well plate.

$3 \times 10^{4}$ modified $\beta 6-1089$ or N-1089 cells were added onto the inner chamber in $200 \mu \mathrm{l}$ serum-free Ham's F12 and incubated for 8 hours at $37{ }^{\circ} \mathrm{C}$. After that the media in the inner and outer chambers were replaced with 200 $\mu \mathrm{l}$ and $500 \mu \mathrm{l} 10 \times$ trypsin EDTA respectively and incubated for 1 hour at $37^{\circ} \mathrm{C}$. The cells were then trypsinised 
and the migrated cells as well as the number of cells remaining in the inner chamber were counted using a CASY counter. The percentage of migrated cells was calculated using the counts of the upper chamber versus total cell number.

\section{Organotypic culture}

Organotypic gels were constructed using rat tail Collagen-I and Matrigel as previously described [27]. Briefly; for 10 gels, $4.9 \mathrm{ml}$ rat tail Collagen-I was mixed with $2.1 \mathrm{ml}$ Matrigel (7:3 v/v ratio), $1 \mathrm{ml} \mathrm{10 \times} \mathrm{DMEM}$ (Sigma-Aldrich, D2429) and $1 \mathrm{ml}$ FBS. The $\mathrm{pH}$ of the solution was neutralised by adding $1 \mathrm{M} \mathrm{NaOH}$ (SigmaAldrich, S8045) drop-wise until the mixture turned an orange-pink colour. $5 \times 10^{6}$ primary normal breast fibroblasts were suspended in $1 \mathrm{ml}$ complete DMEM and added to the neutralised gel mixture. One millilitre of gel mixture was added to 1 well of a 24-well plate and set for 1 hour at $37{ }^{\circ} \mathrm{C}$. Following this, complete DMEM was added drop-wise on top of the gels and equilibrated overnight at $37{ }^{\circ} \mathrm{C}$. The media was aspirated from the top of the gels, $2.5 \times 10^{5}$ modified $\beta 6-1089$ cells suspended in $500 \mu \mathrm{l}$ complete Ham's F12 per gel were added on top of the gels and incubated for 4 hours at 37 ${ }^{\circ} \mathrm{C}$. Then $2.5 \times 10^{5}$ MDA-MB-231 or SUM159 cells in $500 \mu \mathrm{l}$ complete DMEM per gel were added and incubated overnight at $37^{\circ} \mathrm{C}$.

Collagen-I-coated nylon membranes $(100-\mu \mathrm{m}$ pore size) were put on top of steel grids (coated side facing up) in a well of a 6-well plate and the organotypic gels placed on top. The well was filled with complete DMEM until the liquid reached the grid-membrane interface level; media was replenished every 2 days. The gels were harvested after 10 days, fixed in 10\% neutral-buffered formalin (Cell Path, Newtown, UK, BAF-0010-037) overnight and then transferred to $70 \%$ ethanol for 24 hours. Gels were mounted in paraffin and sectioned.

\section{Invadopodia assay (in situ zymography)}

To analyse MEC-derived gelatinase activity an in situ zymography assay was carried out. To prepare the gelatin solution, $178.12 \mathrm{mg} \mathrm{NaCl}$ (Thermo Fisher Scientific, BB358-1), $94.57 \mathrm{mg} \mathrm{NaBH}$ (Sigma-Aldrich, 21,346-2) and $100 \mathrm{mg}$ porcine skin type A gelatin (Sigma-Aldrich, G2500) were dissolved in $50 \mathrm{ml}$ PBS for 1 hour at $37{ }^{\circ} \mathrm{C}$ (pH 9.3), following which $1.8 \mathrm{mg}$ rhodamine was added to the solution and mixed for 2 hours to fluorescently label the gelatin. The gelatin solution was dialysed against PBS for 48 hours using Slide-A-Lyzer Dialysis Cassettes with $10 \mathrm{~K}$ MWCO (Pierce, Rockford, IL, USA, 66830), the PBS being replenished every 24 hours. After dialysis, the gelatin was collected and centrifuged at 1200 rpm for 10 minutes to remove insoluble particles, and then $1 \mathrm{~g}$ sucrose (Thermo Fisher Scientific, 8060153) was added and dissolved. The rhodamine-conjugated gelatin was spun at 1200prm for 10 minutes and then heated to $37{ }^{\circ} \mathrm{C}$. Forty microlitres of solutions (drops) were aliquoted onto a $10-\mathrm{cm}$ tissue culture plate. Thirteenmillimetre coverslips were placed on each drop and incubated for 20 minutes. All incubation steps were performed in the dark. In another dish, $1 \%$ gluteraldehyde solution in PBS (v/v) was aliquoted as $40 \mu \mathrm{l}$ drops. After 20 minutes gelatin-covered coverslips were placed on the gluteraldehyde solution to create a dual layer, and incubated for 15 minutes. The coverslips were placed in a 24-well plate (dual-layered side facing up) and washed three times with $500 \mu \mathrm{l}$ PBS, after which $500 \mu \mathrm{l} 5 \mu \mathrm{g} / \mathrm{ml} \mathrm{NaBH}_{4}$ was added and incubated for 20 minutes then washed as described. For sterilisation, coverslips were incubated with $500 \mu \mathrm{l}$ $70 \%$ ethanol for 5 minutes, washed with PBS, then equilibrated and free aldehydes quenched using $500 \mu \mathrm{l}$ complete Ham's F12 for 20 minutes at $37^{\circ} \mathrm{C}$. Finally, $4 \times 10^{4}$ modified $\beta 6-1089$ or N-1089 cells were added onto the coverslips and incubated for 24 hours.

After incubation, the cells were washed three times with $500 \mu \mathrm{l}$ PBS and fixed in $4 \%$ formaldehyde (PFA, SigmaAldrich, P6148) for 15 minutes at room temperature then washed again as described. Cells were blocked in $0.1 \%$ BSA (v/v) and $0.1 \% \mathrm{NaN}_{3}$ (Thermo Fisher Scientific, S227I) in DMEM (w/v) for 15 minutes in the dark at $4{ }^{\circ} \mathrm{C}$, then stained with FITC-labelled phalloidin (Invitrogen, A22283) for 20 minutes in the dark at room temperature. The coverslips were mounted in ProLong Gold Antifade aqueous mounting reagent (Invitrogen, P36931) with DAPI.

\section{Immunoprecipitation of conditioned media}

Two hundred microlitres of $20 \times$ concentrated CM samples was cleared with $20 \mu \mathrm{l}$ Protein A sepharose beads (GE Healthcare, CL-4B) for 1 hour at $4{ }^{\circ} \mathrm{C}$ with rotation. The samples were spun at $6000 \mathrm{rpm}$ for 2 minutes at $4{ }^{\circ} \mathrm{C}$ and supernatant were collected. Precleared $\mathrm{CM}$ were divided into $100 \mu \mathrm{l}$ aliquots and incubated with $5 \mathrm{mg}$ MMP-8 antibody (R\&D Systems, mAb 908) or mouse IgG (Sigma-Aldrich, I5381) overnight at $4{ }^{\circ} \mathrm{C}$ with rotation.

Antibody treated CM was added to fresh $20 \mu$ l beads and incubated for 4 hours at $4^{\circ} \mathrm{C}$ with rotation. Samples were centrifuged as described. Supernatant were collected and kept as unbound fraction. The remaining pellet was washed with serum-free Ham's F12 as described. In order to remove the precipitates from the beads, $40 \mu \mathrm{l}$ reducing Laemmli buffer was added to $20 \mu \mathrm{l}$ cleared bead pellet and boiled at $100{ }^{\circ} \mathrm{C}$ for $10 \mathrm{mi}-$ nutes then spun once again. Supernatants were collected and kept as bound fraction. Laemmli buffer was added to unbound fraction and boiled at $100{ }^{\circ} \mathrm{C}$ for 5 minutes. Twenty microlitres of prepared sample of bound or 
unbound fractions were loaded and separated on an SDS acrylamide gel and transferred to nitrocellulose as previously described, and probed with anti-MMP-8 or antiV5 antibody.

\section{Immunofluorescence staining}

Cells on coverslips were fixed with 4\% PFA in PBS for 10 minutes at room temperature (RT). Cells were washed three times with $500 \mu \mathrm{l}$ PBS then blocked and permeabilized with $2 \%$ BSA and $0.1 \%$ Triton X-100 in PBS for 15 minutes. Finally, cells were incubated with primary antibody prepared in blocking solution at $1 / 100$ dilution for 1 hour at room temperature. Primary antibodies used were $\alpha 6 \beta 4$ integrin (Merck Millipore, Billerica, MA, USA, MAB1964) and plectin (Epitomics, Burlingame, CA, USA, 1399). Cells were incubated with secondary antibody conjugated with FITC or Cy3 diluted in PBS. (Invitrogen, anti-mouse 546, A11030, anti-rabbit 546, A11035, anti-mouse 488, A11029, anti-rabbit 488, A11008, phalloidin 546, A22283). The cells were mounted in ProLong Gold Antifade aqueous mounting reagent with DAPI. For organotypic cultures, Neso antibody was a kind gift from Prof M. Djamgoz, Imperial College London.

For paraffin-embedded organotypic sections: sections were dewaxed and rehydrated, then boiled in $10 \mathrm{mM}$ Tri-sodium citrate ( $\mathrm{pH} \mathrm{6)}$ ) for 20 minutes. Sections were then incubated in $0.5 \%$ Triton $\mathrm{X}-100$ for 5 minutes at RT. After that the sections were washed with PBS for 1 minute (three times) and blocked with 5\% BSA/PBS for 1 hour at room temperature. Primary antibodies (p63; Dako, M7247, 1/50, Neso; 1/300, Ki67; Novocastra, Newcastle upon Tyne, UK, NCL-L-Ki67-MM1, 1/100) were prepared in blocking solution and incubated for 1 hour at room temperature. After that sections were washed with PBS for 5 minutes (three times). Fluorescently tagged secondary antibodies were prepared in PBS and incubated for 45 minutes at RT. Finally, the sections were washed as described followed by an extra washing step with distilled water and mounted in ProLong Gold Antifade reagent with DAPI. The Ki67 index is calculated as the percentage of Ki67-positive invading breast cancer cells out of the total cell number.

\section{Luciferase reporter assay}

MDA-MB-231 cells transfected with firefly and Renilla luciferase reporter gene fused with PAI-promoter (MDA-MB-231-Luc) were a gift from Dr Caroline Hill (London Research Institute) and cultured in DMEM in the presence of $50 \mu \mathrm{g} / \mathrm{ml}$ blasticidine (Sigma-Aldrich, 15205). MDA-MB-231- Luc cells were seeded onto 96well plates at a density of $4 \times 10^{4}$ cells per well and incubated overnight at $37{ }^{\circ} \mathrm{C}$, followed by serum starvation for 4 hours. $5 \times 10^{4}$ modified $\beta 6-1089$ or N-1089 cells were seeded on top of MDA-MB-231-Luc cells in SFM and co-cultured overnight. The media was removed and cells were washed with $100 \mu \mathrm{l}$ PBS. Cell lysis and luciferase activity quantification was performed using the DualLuciferase Reporter Assay System (Promega, E-1910) according to the manufacturer's instructions.

\section{Zymography}

CM collected from modified $\beta 6-1089$ or N-1089 cells was concentrated as previously described and separated by SDS-PAGE gel containing $3 \mathrm{mg}$ Collagen-I for $50 \mathrm{mi}-$ nutes at $200 \mathrm{~V}$. The gel was developed with developing buffer $[10 \mathrm{ml} 1 \mathrm{M}$ Tris (pH 7.5), $8 \mathrm{ml} 5 \mathrm{M} \mathrm{NaCl}$ (Thermo Fisher Scientific, BP358), $1 \mathrm{ml} 1 \mathrm{M} \mathrm{CaCl}_{2}$ (Sigma-Aldrich, C7902), $1.6 \mathrm{ml}$ 2.5\%Triton X-100 and $179.4 \mathrm{ml}$ sterile distilled water] overnight at $37{ }^{\circ} \mathrm{C}$ and stained with Coomassie Blue R-250 solution (Thermo Fisher Scientific, 20278).

\section{Statistical analysis}

Statistical significance was determined by Student's $t$ test or ANOVA with Bonferroni post-test where appropriate, using Prism (Graphpad Software, San Diego, CA, USA). For immunohistochemical scoring of MMP8 on a ductby-duct basis Fisher's exact test was used on a $2 \times 3$ table. Results were considered as significant with $P$ value less than 0.05 .

\section{Results}

MMP-8 is expressed by normal myoepithelial cells and is lost in DCIS-associated myoepithelial cells

In order to confirm previous observations that the primary source of MMP-8 in normal breast is the MEC population and that it is lost in DCIS-associated MECs, we first undertook to stain normal and DCIS tissue for MMP-8. It can be seen in representative images in Fig. 1a that normal MECs express MMP-8 while MECs associated with DCIS do not. Ducts from seven reduction mammoplasty samples were homogenously positive for MMP-8 (as was hyperplasia) (Additional file 1: Table S1). Thirty-one of $68(45 \%)$ ducts from nine cases of pure DCIS (comprising high, intermediate and low grade) were negative for MMP-8. Thirty-nine of 48 (81\%) of ducts from nine cases of DCIS with invasion were negative for MMP-8 (Additional file 2: Table S2). These data indicate a progressive loss of myoepithelial expression of MMP-8 from normal breast tissue to pure DCIS to DCIS with invasion.

Subsequently, primary normal MECs, luminal epithelial cells (LECs), fibroblasts and their DCIS-associated counterparts were isolated from normal breast and pure DCIS tissue respectively, as described [38], and a nested PCR for MMP-8 was carried out. Normal breast MECs exhibit expression of MMP-8 whereas this expression is lost in DCIS-associated MECs. MMP-8 expression was not 


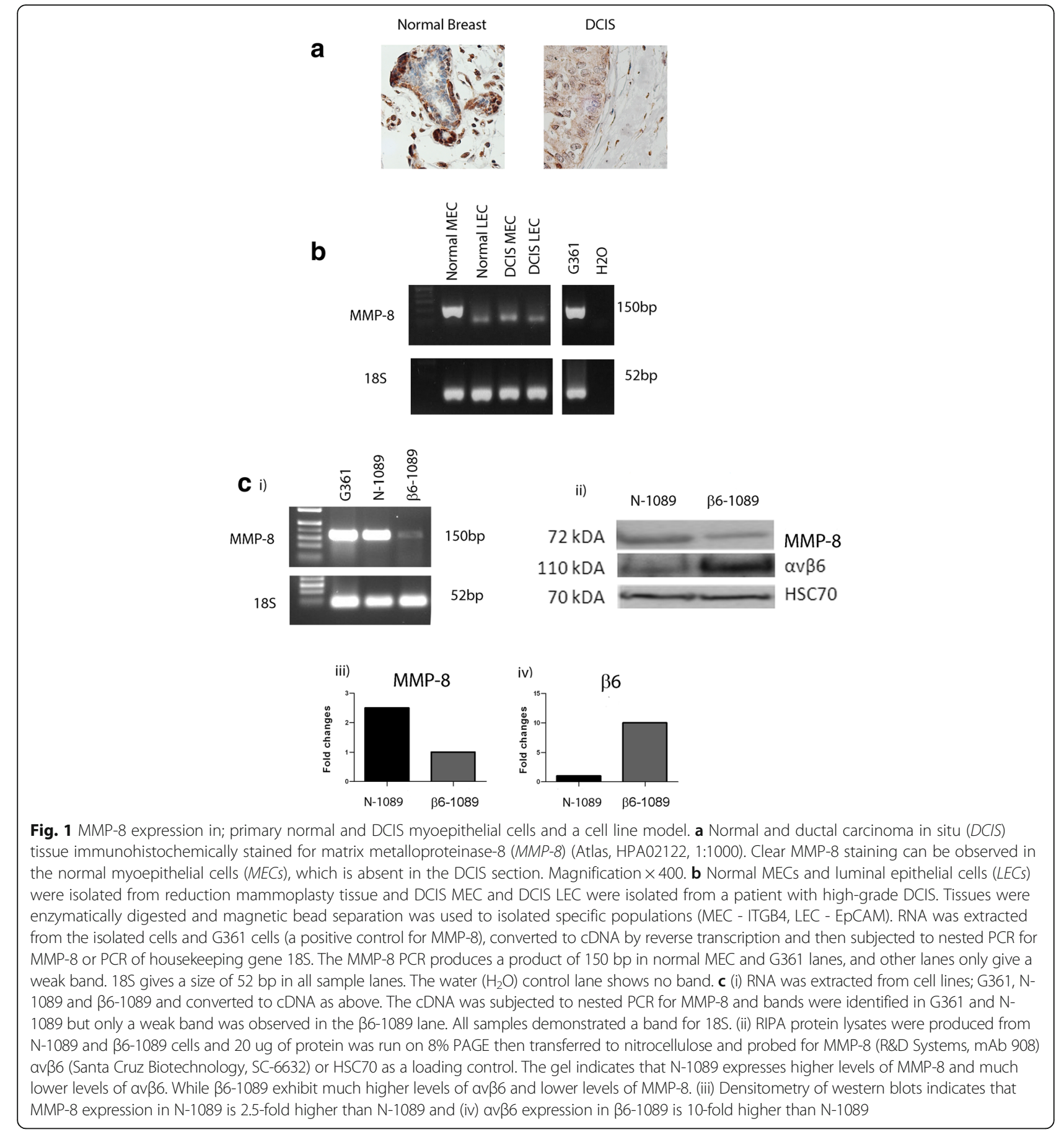

detected in LECs derived from either normal or DCIS tissue (Fig. 1b) or fibroblast populations (not shown). In addition immunofluorescent dual labelling of the myoepithelial-specific protein p63 and MMP-8 demonstrates predominant myoepithelial localisation of MMP8 in a normal breast duct (Additional file 3: Figure S1).

One of the most consistent changes in DCIS-associated MECs is upregulation of the integrin $\alpha v \beta 6$ [41]. Therefore, to establish a model for DCIS-associated MECs, a MEC line over-expressing $\alpha v \beta 6$ integrin ( $\beta 6-1089)$ was generated from a normal, $\alpha \mathrm{v} \beta 6$-negative MEC line (N-1089), as described [27]. To confirm that the $36-1089$ line recapitulates the in vivo phenotype of DCIS, RT Q-PCR for MMP-8 was undertaken in both $\beta 6-1089$ and N-1089 cell lines. MMP-8 expression was downregulated in $\beta 6-1089$ cells as compared to N-1089 cells at both the mRNA (Fig. 1c i and iii) and protein level (Fig. 1c ii and iv), thus reflecting the changes seen in human tissue. 
MMP-8 alters adhesion and migration in DCIS-modified myoepithelial cells in a proteolytic-dependent manner To analyse the gain-of-function effect of MMP-8 in our model of DCIS-modified MEC, MMP- 8 was re-introduced into $36-1089$ cells by plasmid over-expression (MMP-8 WT). To dissect the involvement of proteolytic activity of MMP-8 in its biological role, cells were transfected with an enzymatically inactive form of MMP-8 (MMP-8 EA), generated by a point mutation in the catalytic domain in which an essential glutamic acid residue is changed to alanine [39]. In order to compare protein expression levels, conditioned media $(\mathrm{CM})$ were collected from cells transfected with MMP-8 WT, MMP-8 EA or empty pcDNA4 vector, then concentrated $20 \times$, and immunoprecipitated for MMP-8. Unbound and immunoprecipitated (bound) fractions were subjected to western blotting and similar protein expression levels for WT and EA were observed, with no detection in vector-only CM (Fig. 2a upper panel). MMP-8 is a major collagenase that cleaves Collagen-I [21] therefore the degradative activity of WT and EA forms was examined using Collagen-I zymography. Degradation of Collagen-I was observed only by CM from MMP-8 WT, while MMP-8 EA or empty vector control failed to show any degradation (Fig. 2a lower panel). This confirms the inability of the EA form to cleave Collagen-I.

To analyse whether MMP-8 is involved in MEC adhesion to ECM; MMP-8 WT, MMP-8 EA or control cells were seeded onto different ECM and tracked fluorescently by Calcein AM cell tracker. After 1 hour, non-adherent cells were washed and fluorescence generated from adherent MMP-8 WT and MMP-8 EA cells was normalised to empty vector. Over-expression of MMP-8 WT significantly enhanced adhesion to Fibronectin (Fib), Collagen-I (Col-I), Laminin-I (Lam-I or Lam $\alpha \mathrm{I}-\beta \mathrm{I}-\gamma \mathrm{I})$ and Tenascin-C (Ten-C) whereas there was a significant decrease in adhesion to the $\mathrm{N}$ terminus latency-associated peptide of transforming growth factor beta (TGF- $\beta$ ) (LAP) (Fig. 2b i). LAP is an established ligand for $\alpha v \beta 6$ integrin whereby LAP cleavage by $\alpha v \beta 6$ integrin leads to TGF- $\beta$ activation [42]. In contrast, MMP-8 EA cells, which lack proteolytic activity, showed no evidence of increased ECM adhesion compared to control cells.

To explore the effect of MMP-8 over-expression on MEC migration towards ECM, transwell migration assays were performed. In this system MECs are separated from ECM via a cell-permeable membrane and cells move towards the ECM (Fig. 2b ii). Migration towards Fib, Col-I, Lam-I, Ten-C and LAP was significantly reduced in MMP-8 WT but not in MMP-8 EA cells compared to control empty vector transfected cells. The inability of MMP-8 EA to exert an effect on adhesion or migration indicates that enzymatic activity of MMP-8 is necessary for its function.
To study the loss-of-function effect of endogenous MMP-8 in our normal N-1089 cells, MMP-8 expression was knocked down by siRNA transfection. Knock-down of MMP-8 was confirmed at mRNA and protein level (Fig. 2c i). Adhesion of MEC to Fib, Col-I, Col-IV, Lam-I and Ten-C was significantly reduced in the absence of MMP-8 (Fig. 2c ii) though interestingly there was no significant difference in adhesion to the $\alpha v \beta 6$ ligand LAP.

Transwell migration assays were used to analyse the effect of lack of endogenous MMP-8 on directed migration. MMP-8 knock-down in N-1089 cells led to increased migration towards Col-IV, Lam-I and Ten-C while there was no significant alteration in migration towards other ECM molecules (Fig. 2c iii).

\section{MMP-8 WT modulates a6 $\beta 4$ integrin localisation}

To further investigate the mechanism by which MMP-8 might influence MEC adhesion and migration, the expression and distribution of a major MEC integrin, $\alpha 6 \beta 4$ was examined by immunofluorescence. $\alpha 6 \beta 4$ integrin is a key component of HDs, which are the adhesive structures responsible for stable attachment of the basal cell surface of MEC to the basement membrane (Fig. 3a insert). One unique alteration reported in DCIS MECs is the disassociation of these structures $[43,44]$, $\alpha 6 \beta 4$ localising to invasion-associated actin complexes rather than the adhesive plectin complex [45]. Confocal analysis of dual-labelling for $\alpha 6 \beta 4$ and the HD component plectin revealed that $\alpha 6 \beta 4$ localises more to HD structures in MMP-8 WT compared to MMP-8 EA or control cells (Fig. 3a i). Dual staining of $\alpha 6 \beta 4$ with phalloidin showed that $\alpha 6 \beta 4$ also localises to actin-rich protrusion sites (Fig. $3 \mathrm{~b}$ i) and these retraction fibres were significantly shorter and reduced in number in MMP-8 WT compared to either EA or empty vector cells (Fig. 3b ii and iii) consistent with the less migratory phenotype seen in MMP-8 WT MECs. In addition, on Fibronectin matrix, MMP-8 WT cells showed a greater degree of spreading with a significant increase in occupied area (in pixels) compared to MMP-8 EA or empty vector control cells (Fig. 3b iv).

Immunofluorescence analysis of N-1089 cells following MMP-8 knock-down revealed an increase in the length and number of retraction fibres compared to control knock-down cells, suggesting that MMP-8 inhibits the formation of these fibres (Fig. 3c i, ii and iii).

\section{Myoepithelial MMP-8 WT but not MMP-8 EA reduces breast cancer cell invasion in $2 \mathrm{D}$ system via paracrine interactions}

Normal breast MECs previously have been shown to reduce breast cancer cell invasion through paracrine mechanisms [13]. Transwell invasion assays were used to assess the involvement of MEC-derived MMP-8 in 
a

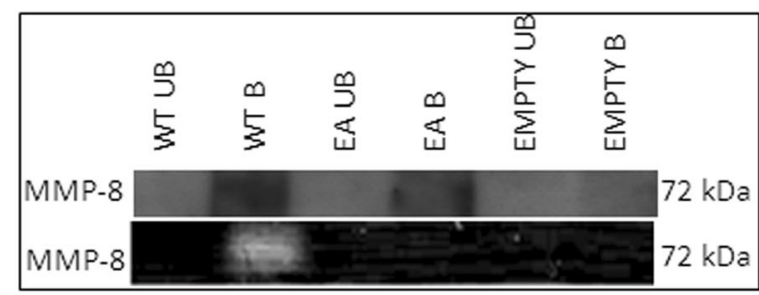

b i)

Adhesion
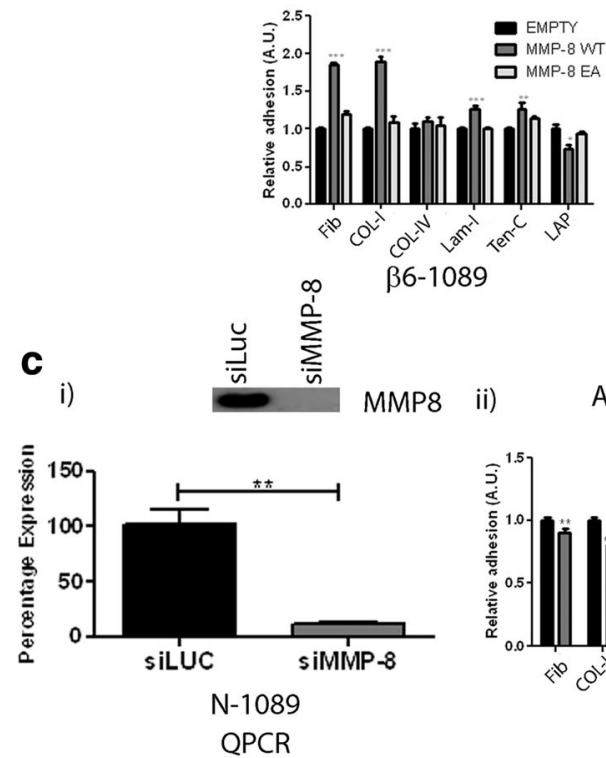

ii)

Migration

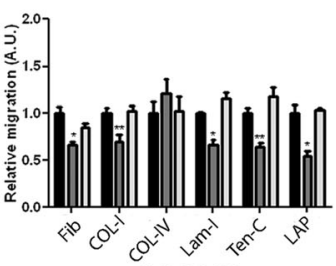

及6-1089 ii) Adhesion

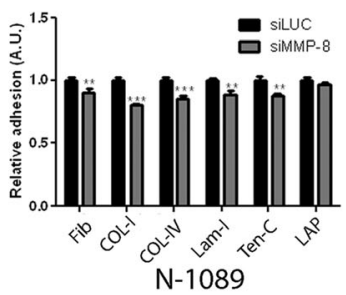

iii)

Migration

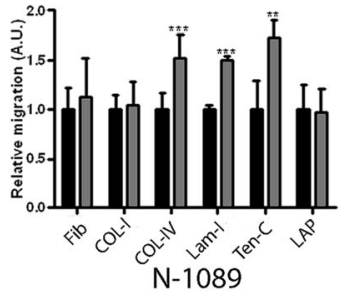

Fig. 2 MMP-8 expression alters myoepithelial cell adhesion and migration to ECM proteins. a Upper panel: immunoprecipitation of matrix metalloproteinase-8 (MMP-8) from 20x concentrated conditioned media of $\beta 6-1089$ transiently transfected with wild-type MMP-8 (WT), inactive point mutant of MMP-8 (EA) or empty vector (EMPTY). Conditioned media (CM) was incubated overnight with MMP-8 antibody (R\& D Systems, mAb 908) or IgG (Sigma-Aldrich) and bound proteins were precipitated with Protein A beads (B) and unbound supernatant was also collected (UB). Samples were separated by 10\% SDS-PAGE and probed with anti-V5 antibody directed to the V5 tag on the transfected MMP-8. Lower panel: Collagen-I zymography. CM was collected from the $\beta 6-1089$ cells as described above and concentrated 20x using $3 \mathrm{~K}$ spin columns. Equal volumes were run by SDS-PAGE containing $3 \mathrm{mg}$ of Collagen-I. The gel was incubated overnight in substrate solution and then stained with Coomassie. Only the lane containing CM from B6-1089 transfected with WT MMP-8 demonstrated a clear band indicating Collagen degradation at the same molecular weight as MMP-8. b (i) Adhesion to ECM proteins. $\beta 6-1089$ cells transiently transfected with empty vector (EMPTY), wildtype MMP-8 (WT) or inactive mutant MMP-8 (EA) were plated on Fibronectin (Fib), Collagen-I (Col-I), Collagen-IV (Col-IM), Laminin-I (Lam-I), Tenascin-C (Ten-C), latency-associated peptide (LAP) or BSA (Control) for 1 hour. Then cells were treated with Calcein AM for 15 minutes before reading the fluorescence. The adhesion is calculated relative to the EMPTY. Expression of WT MMP-8 increased cell adhesion to Fib, Col-I, Lam-I and Ten-C, and decreased adhesion to LAP. The EA transfected cells did not show alterations in adhesion.(ii) $\beta 6-1089$ cells treated in the same way as above were plated onto transwells coated on the underside with the same ECM proteins and cells were allowed to migrate for 8 hours before quantifying the number of cells that were on the top and bottom of the transwell. Migration was calculated relative to the EMPTY. Expression of WT MMP-8 decreased migration towards Fib, Col-I, Lam-I, Ten-C and LAP, while expression of the EA had no effect. c (i) N-1089 cells were transfected with siRNA targeting MMP-8 (siMMP-8) or Luciferase (siluc) as a control. Ninety-six hours after transfection protein and RNA were collected and analysed by western blot and RT Q-PCR respectively. Both the western blot (upper panel) and RT Q-PCR (graph) indicate a reduction in MMP-8 at the protein and mRNA level in response to siMMP-8 treatment as compared to the siLUC control. (ii) N-1089 cells treated with siMMP-8 as described were plated onto the same selection of ECM proteins as previously described in (b). A significant reduction in adhesion to Fib, Col-I, Col-IV, Lam-I and Ten-C was observed in N-1089 transfected with siMMP-8 as compared to N-1089 transfected with siLUC. (iii) N-1089 cells treated with siMMP-8 were also plated on transwells coated with the same selection of ECM proteins as described in (b). The N-1089 transfected with siMMP-8 demonstrated a significant increase in migration towards Col-IV, Lam-I and Ten-C as compared to N-1089 + siLUC. ${ }^{* *} p=0.01,{ }^{* * *} p=0.001$ (Student's $t$ test). Error bars $=\mathrm{SEM}, n=3$ independent experiments

the cross-talk between MECs and breast cancer cells during early invasion through basement membrane, MDA-MB-231 or SUM159 breast cancer cells were seeded onto transwells coated with Matrigel and co- cultured with $36-1089$ cells expressing MMP-8 WT, MMP-8 EA or empty vector control plated onto outer chamber for 24 hours (Fig. 4). A significant reduction in the number of breast cancer cells invading through 


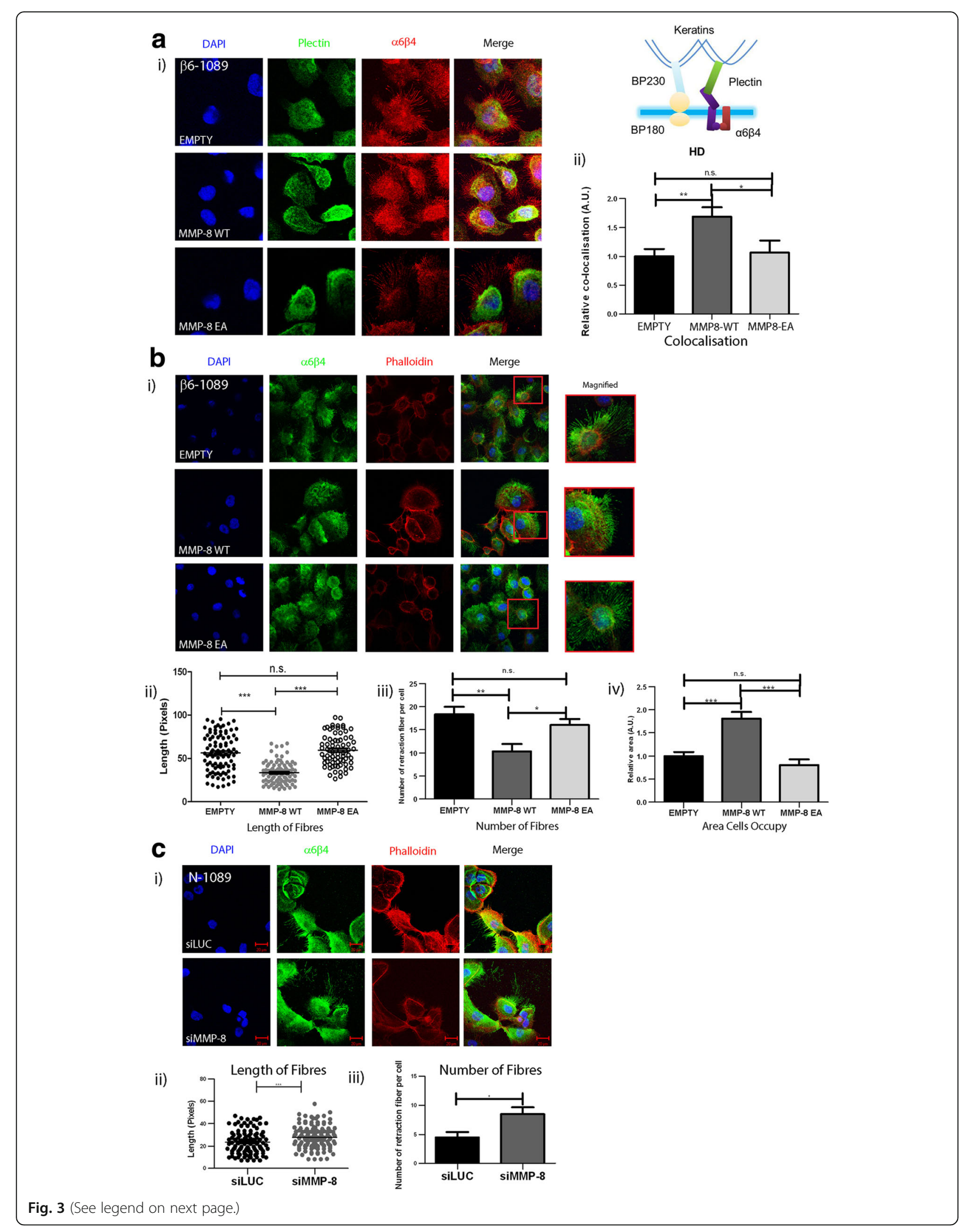


(See figure on previous page.)

Fig. 3 MMP-8 expression alters a6ß4 subcellular distribution and myoepithelial cell morphology. a (i) Confocal images of $\beta 6-1089$ cells transfected with empty vector (EMPTY) wild-type matrix metalloproteinase-8 (MMP-8 WT) or inactive mutant MMP-8 (EA) and grown on Fibronectin for 24 hours then fixed and co-stained for a6ß4 (red) and plectin (green). Insert: cartoon illustrating hemidesmosome (HD) components, indicating the integrin a6 $\beta 4$ associates with plectin to link the complex to the keratin cytoskeleton. (ii) Co-localisation of a6ß4 and plectin was determined by quantifying the number of yellow pixels per field of view in each condition then expressed as a ratio as compared to EMPTY. $\beta 6-1089$ transfected with WT demonstrated a significant increase in a6ß4 and plectin co-localisation, while the $\beta 6-1089$ transfected with EA exhibited no change as compared to EMPTY. b (i) Confocal images of $\beta 6-1089$ cells transfected with empty vector (EMPTY) wild-type MMP-8 (WT) or inactive mutant MMP-8 (EA) and grown on Fibronectin for 24 hours then fixed and co-stained for a6ß4 (green) and phallodin (red). (ii) Morphological features of the transfected $\beta 6-1089$ were analysed and length of trailing fibres was noted to be altered. Analysis of the length of these fibres indicated that B6-1089 transfected with MMP-8 WT significantly reduced the fibre length as compared to $\beta 6-1089$ transfected with empty vector or MMP-8 EA. (iii) Analysis of the number of these fibres per cell also demonstrated a significant reduction in $\beta 6-1089$ transfected with MMP-8 WT as compared to $\beta 6-1089$ transfected with empty vector or MMP-8 EA. (iv) The final morphological alteration analysed was the physical space the cells occupied, the relative area occupied by $\beta 6-1089$ transfected with MMP-8 WT was significantly larger than that occupied by $\beta 6-1089$ transfected with empty vector or MMP-8 EA. c (i) Confocal images of N-1089 cells transfected with siRNA targeting MMP-8 (siMMP-8) or Luciferase (siluc) as a control grown on Fibronectin for 24 hours then fixed and co-stained for a6ß4 (green) and phallodin (red). (ii) Trailing fibre length was significantly longer in N-1089 transfected with siMMP8 as compared to siLUC. (iii) There were significantly more trailing fibres per cell in the N-1089+ siMMP8 group as compared to $\mathrm{N}-1089$ transfected with siLUC. ${ }^{*} p=0.05^{* *} p=0.01,{ }^{* * *} p=0.001$ (Student's $t$ test). Error bars $=\mathrm{SEM}, n=3$ independent experiments

a

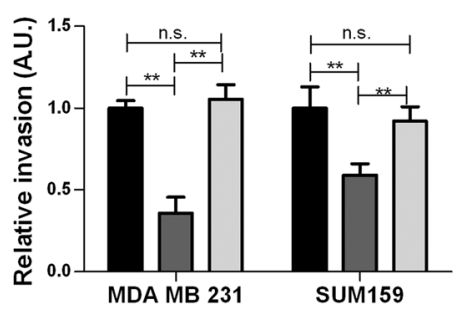

C

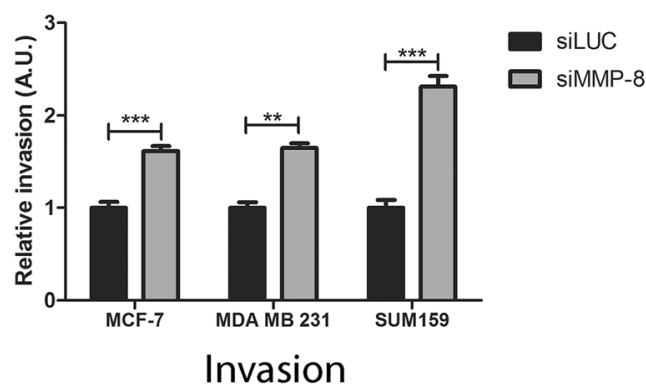

b

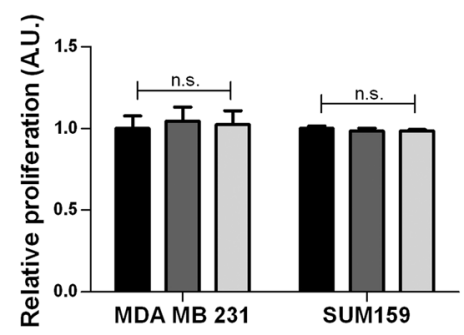

d

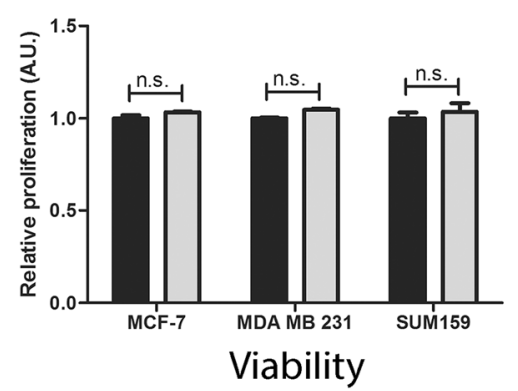

Fig. 4 MMP-8 expression by myoepithelial cells has a paracrine effect on tumour cell invasion. a $36-1089$ cells transfected with empty vector (EMPTY) wild-type matrix metalloproteinase-8 (MMP-8 WT) or inactive mutant MMP-8 (EA) were plated into 24-well plates and grown in serumfree media for 24 hours. Transwells coated with Matrigel were placed into the wells and MDA-MB-231 or SUM159 cells were placed on top of the Matrigel. After 24 hours the transwells were removed and the number of invading cancer cells counted. Invasion was calculated relative to the 36-1089 transfected with empty vector. MDA-MB-231 and SUM159 cells exhibited a significant reduction in invasion when in the presence of $\beta 6-$ 1089 transfected with WT cells, this was not observed with the $\beta 6-1089$ transfected with EA cells. $\mathbf{b}$ MTS assay for viability on MDA-MB-231 and SUM159 cells grown for 24 hours in the presence of conditioned media (CM) from $\beta 6-1089$ cells transfected with empty vector (EMPTY) wild-type MMP-8 (WT) or inactive mutant MMP-8 (EA). No difference was observed between any of the groups relative to $\beta 6-1089$ transfected with empty vector. c Transwells were set up as described above with N-1089 cells transfected with siRNA targeting MMP-8 (siMMP-8) or Luciferase (siluc) were plated into the bottom wells. MCF-7, MDA-MB-231 and SUM159 cells were plated into Matrigel-coated transwells above. After 24 hours (or 48 hours for MCF-7) the transwells were removed and the number of invading cancer cells counted. Invasion was calculated relative to the N-1089 transfected with siLUC. MDA-MB-231 and SUM159 cells exhibited a significant increase in invasion when in the presence of N-1089 transfected with siMMP-8. d MTS assay for viability on MCF-7, MDA-MB-231 and SUM159 cells grown for 24 hours in the presence of conditioned media (CM) from N-1089 cells transfected with siRNA targeting MMP-8 (siMMP-8) or Luciferase (siluc). No difference was observed between the two groups. ${ }^{* *} p=0.01$, (Student's $t$ test). Error bars $=\operatorname{SEM}, n=3$ independent experiments 
Matrigel in the presence of $\beta 6-1089$ cells expressing MMP-8 WT was observed compared to cells transfected with EA or empty vector (Fig. 4a). Transwells carried out using ER+ cell line MCF-7 showed no reduction in invasion (data not shown) - however these cells exhibited a low degree of invasion and therefore it can be speculated that the invasion could not be reduced any further. These results indicate that the invasionsuppressor activity exhibited by MMP-8 WT MECs is dependent upon MMP-8 enzymatic activity, as MMP-8 EA does not influence tumour cell invasion. To show a direct effect of MMP-8 on breast cancer cell invasion, recombinant MMP-8 containing serum-free media was used in the outer chamber, which resulted in a significant decrease in breast cancer cell invasion similar to that seen with MMP-8 WT MECs (data not shown). In order to eliminate the possibility that the reduced invasion was a reflection of altered cell number of breast cancer cells, MDA-MB-231 and SUM159 cells were treated with CM collected from modified MECs after 24 hours of starvation (the same time duration as the invasion assays). The tumour cells were analysed in an MTS assay, which revealed no differences in relative cell number of the MDA-MB-231 or SUM159 cells (Fig. 4b). When the MMP-8 substrate Col-I was replaced with Matrigel in transwell invasion assays, there also was a significant downregulation in breast cancer cell invasion towards MMP-8 WT over-expressing $\beta 6-1089$ cells, but not MMP-8 EA or empty vector transfected cells (data not shown).

To dissect whether loss of normal MEC-derived MMP8 has an influence on breast cancer cell invasion, MCF-7, MDA-MB-231 and SUM159 cells were co-cultured with N-1089 control cells following knock-down of MMP-8 in a transwell setup. This demonstrated that breast cancer cell invasion was significantly enhanced in the absence of MMP-8 (Fig. 4c). These data support the earlier contention that reduction in MCF-7 invasion was too small to measure, as co-culturing with MECs knocked down for MMP-8 enhanced MCF-7 invasion significantly. No significant difference in breast cancer cell number was demonstrated in the presence of $\mathrm{N}-1089$ control or MMP-8 knock-down CM (Fig. 4d), supporting the concept that MMP-8 suppresses invasion and does not alter cell number.

\section{Myoepithelial MMP-8 WT suppresses breast cancer cell invasion in 3D organotypic culture}

In order to recapitulate the DCIS-related stromal microenvironment, 3D organotypic cultures were constructed from Col-I/Matrigel gels embedded with primary normal breast fibroblasts and overlaid with modified MECs and MDA-MB-231 or SUM159 breast cancer cells, to reflect the juxtapositioning of these cell populations in breast tissue (Fig. 5). After 10 days of incubation, gels were fixed, sectioned and stained with hematoxylin and eosin (H\&E) (Fig. 5a). In order to discriminate the invading breast cancer cells from modified 36-1089 cells, organotypic cultures were stained for the invasive breast cancer cell marker Neso [46], which selectively detects the tumour cells invading into the gel (Additional file 4: Figure S2). An invasion index was quantified by combining the depth, number and area occupied by invaded cells and normalised to invasion observed when breast cancer cells were co-cultured with $36-1089$ cells transfected with empty vector control. There was a significant decrease in tumour cell invasion only in the presence of MMP-8 WT transfected $\beta 6-1089$ cells (Fig. 5b). To confirm that the reduced invasion index does not reflect decreased proliferation, organotypic gels were stained for the proliferation marker Ki67. The Ki67 index indicates that proliferation is not significantly altered in any of the transfection groups (Fig. 5c).

\section{MMP-8 modifies MMP-9 activity}

We previously have identified increased MMP-9 activity in $36-1089$ cells compared to $\mathrm{N}-1089$, downstream of enhanced TGF- $\beta$ signalling [41]. Furthermore it has been reported that MMP-9 can cleave the extracellular domain of $\alpha 6 \beta 4$ and in turn interfere with HD assembly [47]; we therefore analysed the expression levels and proteolytic function of MMP-9 in $36-1089$ cells, with and without MMP-8 over-expression. RT Q-PCR revealed no significant difference in MMP-9 mRNA levels between empty, MMP-8 WT or MMP-EA transfected cells (data not shown). To study whether the proteolytic activity of MMP-9 is altered upon MMP-8 expression, modified $\beta 6-1089$ cells were grown on rhodaminelabelled MMP-9 substrate gelatin for 24 hours and then fixed and stained with FITC-conjugated phalloidin. The degraded matrix area was quantified, and demonstrated a significant reduction in gelatin degradation in $\beta 6-1089$ cells transfected with MMP-8 WT compared to the EA form or empty vector (Fig. 6a i and ii). There was no difference in cell number per field among different transfection groups (Fig. 6a iii).

In order to understand whether MMP-8 loss in N1089 cells can influence MMP-9 function, modified N1089 cells were seeded on MMP-9 substrate as described and gelatinase activity was quantified. The area of degraded gelatin was significantly increased in MMP-8 knocked down cells, with no change in cell number (Fig. 6b i-iii).

To further investigate the MMP-9 activity, MMP-9 was knocked down by siRNA treatment in the MMP-8 knocked down N-1089 cells (MMP-9 knock-down was verified by RT Q-PCR, data not shown) or cells were treated with an MMP-9 inhibitor (Fig. 6c). Gelatin 

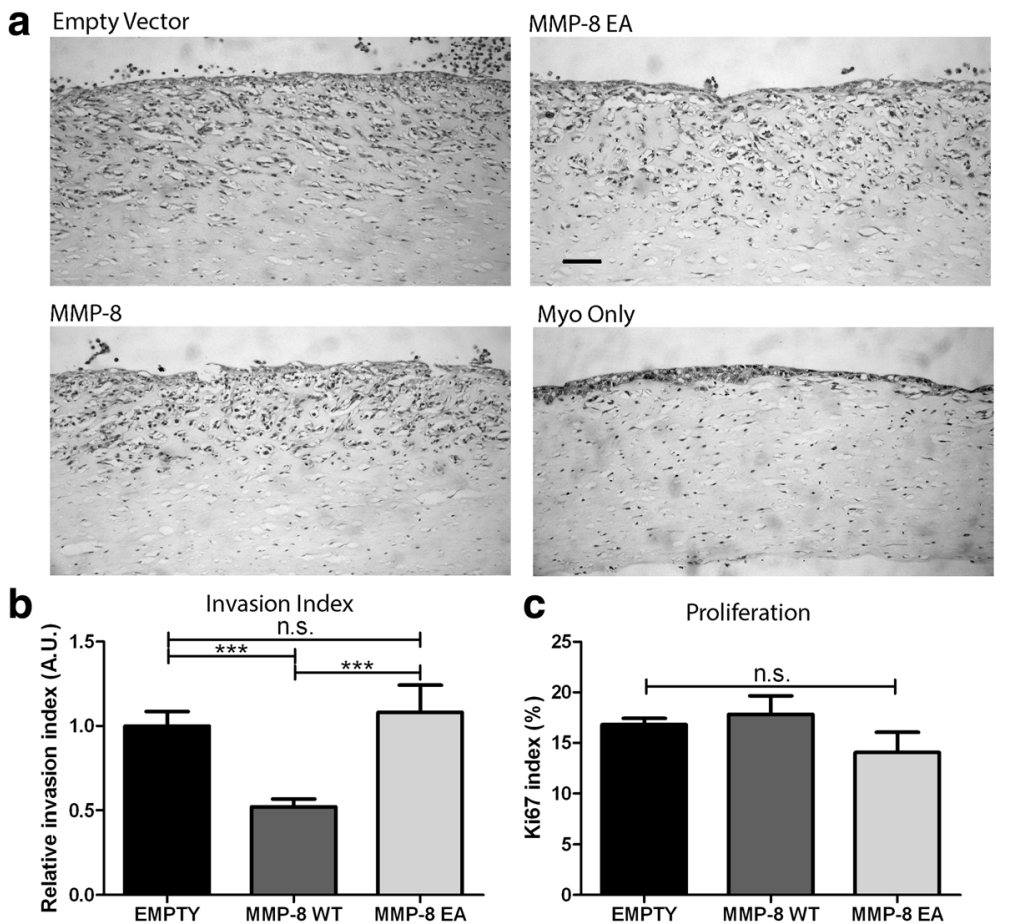

Fig. 5 MMP-8 expression in myoepithelial cells alters tumour cell invasion in 3D organotypics. a 3D organotypic microenvironment of the breast was created by mixing collagen and Matrigel with normal breast fibroblasts. $\beta 6-1089$ cells transfected with empty vector (EMPTY) wild-type matrix metalloproteinase-8 (MMP-8 WT) or inactive mutant MMP-8 (EA) were plated on top of the gel and allowed to attach, then MDA-MB-231 cells were plated on top of the transfected $\beta 6-1089$ cells. Organotypics were grown at an air/liquid interface for 10 days then fixed and embedded in paraffin. Section were taken and stained with H\&E and images were taken for analysis. $\mathbf{b}$ An invasion index was determined for each condition by multiplying; the average depth of invasion (from multiple points in each section), the number of invading aggregates and the size of the aggregates. MDA-MB-231 cells grown with $\beta 6-1089$ transfected with WT exhibited a significantly reduced invasion index relative to the $\beta 6-1089$ transfected with EMPTY and EA. c Organotypic sections were stained for Ki67 and the positively staining cells were quantified to determine the level of proliferation in each condition. There was no difference observed between any of the groups. ${ }^{* * *} p=0.001$ (Student's $t$ test). Error bars $=\mathrm{SEM}, n=3$ independent experiments

degradation was significantly downregulated upon MMP9 knock-down in siMMP-8-treated N-1089 cells. In addition, there was a dose-dependent decrease in degraded gelatin area in relation to increasing concentrations of MMP-9 inhibitor. There was no difference in gelatin degradation in DMSO vehicle control compared to siMMP-8 treatment suggesting that the increased gelatin degradation is derived from increased MMP-9 activity after MMP-8 knock-down.

\section{MMP-8 reduces TGF- $\beta$ signalling}

To study the effect of MMP-8 expression on TGF- $\beta$ ignalling, modified $\beta 6-1089$ cells were treated with $5 \mathrm{ng} /$ $\mathrm{ml}$ active TGF- $\beta 1$ for 5,10 and 15 minutes. As a readout for TGF- $\beta$ signalling activity, the phosphorylation levels of TGF- $\beta$ downstream element SMAD- 2 was evaluated by WB. The expression levels of total and phosphorylated forms of SMAD-2 were normalised to that of actin. The phosphorylation levels of SMAD-2 were decreased in 36-1089 cells over-expressing MMP-8 WT as compared to empty vector control and EA mutant cells at 5 minutes. There also was a reduction in phospho-SMAD2 in 36-1089 cells over-expressing MMP-8 EA as compared to empty vector at 15 minutes. The phosphorylation levels of SMAD-2 in MMP-8 EA were higher than phospho-SMAD-2 levels in MMP-8 WT at 5 minutes (Fig. 6d i and Additional file 5: Figure S3i).

To investigate the effect of loss of MMP- 8 on TGF- $\beta$ downstream signalling, modified N-1089 cells, with MMP-8 knock-down, were treated with active TGF- $\beta 1$ as described. This revealed an increase in phosphorylated SMAD-2 in MMP-8 knocked-down N-1089 cells compared to control siRNA transfected cells at 5, 10 and 15 minutes (Fig. 6d ii and Additional file 5: Figure S3ii), suggesting that MMP- 8 reduces TGF- $\beta$ signalling, and this may not be dependent on enzymatic activity.

\section{Discussion}

Transition of DCIS to invasive cancer is a critical step in the natural history of breast cancer, converting a potentially curable lesion to a life-threatening disease. Only around half of DCIS lesions will progress to invasive 


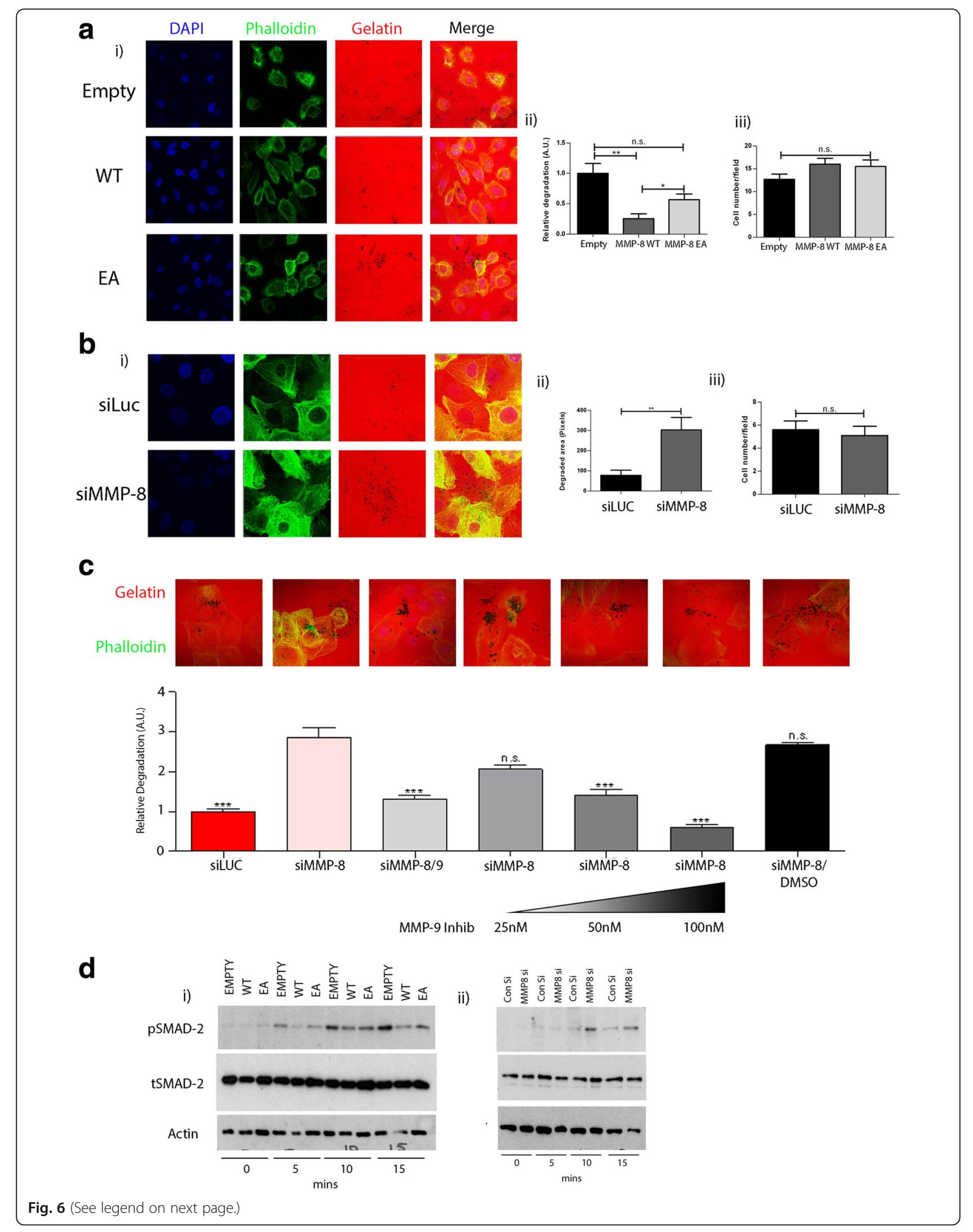




\begin{abstract}
(See figure on previous page.)
Fig. 6 MMP-8 expression in myoepithelial cells alters MMP-9 expression/function and TGF- $\beta$ signalling. a (i) Confocal images of $\beta 6-1089$ cells transfected with empty vector (EMPTY) wild-type matrix metalloproteinase-8 (MMP-8 WT) or inactive mutant MMP-8 (EA) and grown on rhodamine-tagged gelatin (red) for 24 hours then fixed and stained with FITC-conjugated phallodin (green). (ii) Gelatinase activity was quantified by measuring the total size of the black spots (degraded gelatin) per field of view relative to the $\beta 6-1089$ transfected with EMPTY. There was a significant reduction in gelatin degradation in $\beta 6-1089$ transfected with WT and EA compared to $\beta 6-1089$ transfected with EMPTY, albeit the reduction in $\beta 6-1089$ transfected with EA was not as marked. (iii) The number of cells per field of view was determined and no significant difference was noted between the groups. b (i) Confocal images of N-1089 cells transfected with siRNA targeting MMP-8 (siMMP-8) or Luciferase (siluc) and grown on rhodamine-tagged gelatin (red) for 24 hours then fixed and stained with FITC-conjugated phallodin (green). (ii) Gelatin degradation was significantly increased in N-1089 transfected with siMMP-8 as compared to siLUC. (iii) Quantification of the number of cells per field of view indicated no difference between the two groups. c Confocal images of N-1089 cells transfected with siRNA targeting MMP-8 (siMMP-8) and MMP-8 and MMP-9 (siMMP-8/9) or Luciferase (siLuc) and grown on rhodamine-tagged gelatin (red) for 24 hours with or without an MMP-9 inhibitor at increasing concentration then fixed and stained with FITC-conjugated phallodin (green). The graph indicates relative gelatin degradation increases in N-1089 transfected with siMMP-8, this increase is significantly reduced when both MMP-8 and MMP-9 are knocked down (siMMP-8/9). The increase in gelatin degradation can also be significantly reduced, in a dose-dependent manner, with an MMP-9 inhibitor. $\mathbf{d}$ (i) Western blots for SMAD-2 on protein extracted from $\beta 6-1089$ cells transfected with empty vector (EMPTY), wild-type MMP-8 (WT) or inactive mutant MMP-8 (EA) after treatment with TGF- $\beta(5 \mathrm{ng} / \mathrm{ml})$ for 5, 10 and 15 minutes. $\beta 6-1089$ transfected with empty vector exhibit higher levels of Phospho (p)SMAD-2 at all time points than the $\beta 6-1089$ transfected with WT, while the $\beta 6-1089$ transfected with EA appear to show moderate expression. Total (t)SMAD-2 levels are similar in all lanes as is the actin loading control. (ii) Western blots for SMAD-2 on protein extracted from of N-1089 cells transfected with siRNA targeting MMP-8 (siMMP-8) or Luciferase (siLuc) after treatment with TGF- $\beta$ ( $5 \mathrm{ng} / \mathrm{ml}$ ) for 5, 10 and 15 minutes. N-1089 transfected with siMMP-8 exhibit higher expression of pSMAD-2 at 10 and 15 minutes than the N-1089 transfected with siLUC. The tSMAD2 and actin expression levels appear to be consistent. ${ }^{*} p=0.05^{* *} p=0.01,{ }^{* * *} p=0.001$ (Student's $t$ test). Error bars $=\mathrm{SEM}, n=3$ independent experiments
\end{abstract}

cancer during a woman's lifetime, but there is a lack of robust predictive markers to stratify patient management $[1,48,49]$. Molecular studies have indicated a consistent similarity between DCIS tumour cells and their invasive counterparts, showing that DCIS cells are as genetically advanced as invasive cancer. This has focused attention on the microenvironment, which shows evidence of being significantly altered in DCIS compared to normal tissue $[6,7,50,51]$. A unique component of the breast microenvironment is the MEC population. In the normal breast, MECs form a stable interface with the basement membrane, regulate epithelial cell polarity and exert a multifaceted tumour-suppressor role $[9,52-55]$. We, and others, have shown that MECs are altered in DCIS and we recently demonstrated that upregulation of the integrin $\alpha v \beta 6$ by DCIS-associated MEC confers tumourpromoter activity on MECs through TGF- $\beta$-mediated upregulation of MMP-9 [27].

Whilst many MMPs exert tumour-promoter effects, a greater understanding of metalloproteinase biology has indicated that some family members have tumoursuppressor effects. MMP-8 was identified as a tumour suppressor nearly a decade ago when the MMP- 8 knockout mouse was found to be more susceptible to skin tumuorigenesis as compared to a WT mouse [28]. There is also strong evidence for a role in tumour prevention in breast cancer, melanoma and squamous cell carcinoma [22, 26, 28, 29, 31, 32, 56-59]. Particularly in melanoma; MMP-8 is frequently mutated by loss of heterozygosity $(\mathrm{LOH})$, which is a hallmark for tumour-suppressor proteins [22]. In addition this mutation results in a significant decrease in enzymatic activity and a concomitant loss of its cancer-protective role [26]. However understanding the mechanism by which MMP-8 mediates this antitumour role is incomplete. In the breast, MMP-8 is expressed by the MEC population, and we identified loss of MMP-8 in DCIS-associated MECs [22]. This study aimed to address the role of MMP- 8 in MECs and the impact of its loss on MEC phenotype and tumour-suppressor function.

We used purified cell populations from normal and diseased breast to confirm MECs as the primary source of MMP-8 in the normal breast, and its loss in DCISassociated MECs. We demonstrated similar loss of expression in a cell line model of DCIS-associated MEC generated by over-expression of $\beta 6$ integrin ( $\beta 6-1089$ cells) compared to its normal MEC counterpart (N1089). These models were used to investigate gain-offunction effects, through over-expression of MMP-8 or an inactive mutant (EA, which carries a point mutation in catalytic site) in $36-1089$, and loss-of-function effects, through MMP-8 knock-down in N-1089 cells.

In normal breast, MECs have a central role in preserving normal tissue architecture, [60], and correct MECmatrix interactions are crucial for MECs to maintain cell polarity in the context of tumour suppression [52-54, 61]. We therefore aimed to investigate if MMP-8 is involved in ECM sensing and response.

When modified $\beta 6-1089$ cells were seeded on different ECM components, WT MMP-8 but not the inactive MMP-8 EA resulted in a significant increase in MEC adhesion to ECM proteins including Fibronectin, Collagen-I, Laminin-I and Tenascin-C. Furthermore, transwell migration assays indicated that MEC migration towards Fibronectin, Collagen-I, Laminin-I and TenascinC was significantly downregulated only in MMP-8 WT 
cells, suggesting that MMP-8 contributes to stable anchorage of MECs to ECM, reflecting their role in normal breast. Both adhesion to and migration towards LAP, an established ligand of $\alpha v \beta 6$ integrin [42], was consistently and significantly reduced, possibly reflecting a reduction in $\alpha v \beta 6$ integrin activity. Similarly, knock-down of MMP8 in N-1089 cells resulted in decreased adhesion and enhanced migration to ECM proteins, confirming a role for MMP-8 in matrix adhesion.

MEC attachment to basement membrane is achieved through HDs, which are stable adhesions critical for the integrity of epithelial cell monolayers. The integrin $\alpha 6 \beta 4$ nucleates HD formation through linkage to plectin and the intermediate filament cytoskeleton $[43,62]$. Disassociation of HDs and localisation of $\alpha 6 \beta 4$ to actin-rich protrusions are characteristics of the acquisition of a migratory phenotype in basal cells, and has been well studied in migrating keratinocytes during wound healing [63-65]. Since loss of HD formation is recognised in DCIS-associated MEC [43], we sought to investigate the effect of MMP-8 on the subcellular localisation of $\alpha 6 \beta 4$. This revealed that, in MMP-8 WT over-expressing cells, there was significantly greater co-localisation of $\alpha 6 \beta 4$ to HD-associated plectin, with shorter and reduced number of retraction fibres, corresponding to a reduced migratory phenotype. Moreover, phalloidin staining of modified 36 1089 cells showed that MMP-8 WT cells significantly spread more on Fibronectin, in keeping with a more adhesive phenotype. In keeping with this, knock-down of MMP-8 in N-1089 cells resulted in significantly longer and increased number of retraction fibres compared to control cells, which we speculate indicates the acquisition of a more migratory phenotype.

Compromise of the MEC-basement membrane barrier is a key event in progression of DCIS to invasive cancer. Since MMP- 8 impacts on MEC adhesion and HD formation, we sought to analyse whether altered MMP-8 expression by MEC influences their tumour-suppressor activity. Transwell invasion assays were used, in which MCF-7, MDA-MB-231 or SUM159 breast cancer cells were placed onto a Matrigel-coated porous membrane and allowed to invade towards MEC populations. A significant decrease in tumour invasion was observed for MDA MD 231 and SUM159 cells co-cultured with MMP-8 WT over-expressing $\beta 6-1089$ compared to empty vector and MMP-8 EA, suggesting that MMP-8 contributes to MEC invasion-suppressor effect. This was further supported by enhanced transwell invasion for all tumour cells in the presence of N-1089 MMP-8 knockdown cells. A similar effect was detected in a more physiologically relevant 3D organotypic model reflecting the microenvironmental conditions of DCIS, incorporating a fibroblast populations as well as the MEC-tumour cell bilayer $[41,66]$.
Cooperation of tumour cells with the microenvironment is required to breach basement membrane [19, 62, 67]. Thus altered proteolytic activity of MECs could contribute to the invasive phenotype of breast cancer cells. We previously have shown that $\beta 6-1089$ cells promote tumour invasion through TGF- $\beta$-mediated upregulation of MMP-9 [41]. A number of studies have indicated that MMP-8 can modulate TGF- $\beta$ signalling $[68,69]$, and since we show that over-expression of MMP-8 WT in $\beta 6-1089$ cells modifies their invasion-promoter effect, we investigated whether MMP-8 could influence TGF- $\beta$ signalling and MMP-9 expression or activity in this cell population. This showed that phosphorylation of SMAD-2 was downregulated in 36-1089 cells expressing MMP-8 WT and enhanced in N-1089 cells following MMP-8 knock-down, supporting a role for MMP-8 in dampening TGF- $\beta$ signalling. However, MMP-8 WT or EA did not have a significant effect on MMP-9 expression, though when modified $\beta 6-1089$ cells were incubated on fluorescently labelled gelatin, the substrate of MMP-9, the area of degradation was significantly abrogated by MMP-8 WT cells. In contrast, gelatin degradation was significantly enhanced by knockdown in N-1089 cells, and importantly this effect could be rescued by MMP-9 inhibition or by MMP-9 knock-down. This suggests some form of inhibitory interaction between MMP-8 and MMP-9: it previously has been shown that MMP-8 can establish a complex with MMP-9 but the function of this complex remains elusive [30].

In tissues MECs of normal and benign ducts are consistently positive for MMP-8, whilst there is a significant progressive loss of this metalloproteinase through pure DCIS to DCIS with co-existing invasion ( $p=0.001$, Additional file 2: Table S2). This finding should be further validated on a larger cohort ideally with long-term follow-up.

\section{Conclusions}

Overall these data indicate that MEC-derived MMP-8 acts as a tumour suppressor by promoting HD formation and enhancing cell adhesion to ECM, thus maintaining tissue architecture, and concomitantly downregulating breast cancer cell invasion in a proteolytic-dependent manner. MMP-8 appears to downregulate the TGF- $\beta$ signalling evident in DCIS-associated MEC, and opposes MMP9 activity, which we show promotes breast cancer cell invasion [27] and also has been shown to prevent HD formation [43].

Since both $\alpha v \beta 6$ integrin [27] and MMP- 8 are key regulators of myoepithelial pro- and anti-tumorigenic activity, these data support the development of a risk stratification profile that could be used clinically to tailor management of patients with DCIS. This is an approach currently being addressed by the LORIS trial [70]. 


\section{Additional files}

Additional file 1: Table S1. Summary of breast tissue examined for MMP8. (DOC $27 \mathrm{~kb}$ )

Additional file 2: Table S2. Duct-by-duct analysis. (DOC $28 \mathrm{~kb}$ ) Additional file 3: Figure S1. Dual immunofluorescent staining of a normal breast duct showing MMP-8 (green Atlas, HPA02122,1:200) and p63 (red Abcam, Ab735, 1:50). The image shows predominant myoepithelial localisation of MMP-8. (TIF $7068 \mathrm{~kb}$ )

Additional file 4: Figure S2. Images of one representative organotypic gel fluorescently stained for myoepithelial marker p63 (green) (noninvading cell layer), nuclear marker DAPI (blue) and marker of invasive breast cancer cells Neso (red). From left to right images show gels comprising fibroblasts, MDA-MB-231 cells and MECs transfected with Empty Vector, MMP8 WT and MMP8 EA. The final panel shows a gel comprised of fibroblasts and MECs alone. Non-transfected MECs were used in the last panel. (TIF $986 \mathrm{~kb}$ )

Additional file 5: Figure S3. (i) Densitometry quantifying pSMAD2 versus tSMAD2 normalised to the loading control. MECs transfected with MMP-8 WT show a marked reduction of PSMAD2 compared to Empty Vector and MMP-8 EA at 5 minutes. (ii) Densitometry quantifying PSMAD2 versus tSMAD2 normalised to the loading control. MECs transfected with siRNA to MMP-8 demonstrated a markedly stronger PSMAD2 signal compared to control siRNA (siLUC). (TIF $336 \mathrm{~kb}$ )

\section{Abbreviations}

CM: Conditioned media; Col-I: Collagen-I; Col-IV: Collagen-IV; DCIS: Ductal carcinoma in situ; EA: Inactive mutant; ECM: Extracellular matrix Fib: Fibronectin; HD: Hemidesmosomes; IBC: Invasive breast cancer; LamI: Laminin-I; LAP: Latency-associated peptide; LEC: Luminal epithelial cell; MEC: Myoepithelial cell; MMP-8: Matrix metalloproteinase-8; SFM: Serum-free media; Ten-C: Tenascin-C; TGF- $\beta$ : Transforming growth factor beta; WT: Wildtype

\section{Acknowledgements}

We give special thanks to all of the patients who consented to provide us with material, without their cooperation this study could not have been done.

\section{Funding}

MS was funded by a Breast Cancer Now (formerly Breast Cancer Campaign) PhD studentship. JG and LH are funded as part of the Breast Cancer Now Tissue Bank Cell Culture Programme.

\section{Availability of data and materials}

All data generated or analysed during this study are included in this published article and its supplementary information files. The patient cases dataset used is not publically available for data protection, but is available from the corresponding author on reasonable request.

\section{Authors' contributions}

MS and MA participated in the design of the study, carried out the experiments, analysed the data and drafted the manuscript. AU carried out MMP8 IHC and helped with analysis. JG and LH characterised and provided the primary cells for the experiments. JD and ST provided MMP-8 WT and MMP-8 EA vectors and provided input to the experimental design. JFM provided expertise in organotypic assays and in the in situ zymography, as well as critical evaluation of the manuscript. S-JS provided statistical analysis support. DRE and JLJ were joint Pls of the study, participating in the design and critical evaluation of data as well as drafting the manuscript. All authors have read and approved the final manuscript

\section{Authors' information}

Not applicable

\section{Competing interests}

The authors declare they have no competing interests.

\section{Consent for publication}

No individual level data are presented in this manuscript.

\section{Ethics approval and consent to participate}

Breast tissue samples were obtained from surgical specimens from patients undergoing breast surgery at Barts Health NHS Trust London. The study was performed following patient consent and approval from the local research ethics committee (reference: 05/Q0403/199 and 09/H075/39).

\section{Publisher's Note}

Springer Nature remains neutral with regard to jurisdictional claims in published maps and institutional affiliations.

\section{Author details}

${ }^{1}$ Translational Cancer Discovery Team, CRUK Cancer Therapeutics Unit, Institute of Cancer Research, 15 Cotswold Road, Sutton, Surrey SM2 5NG, UK. ${ }^{2}$ Centre for Tumour Biology, Barts Cancer Institute, John Vane Science Centre, Charterhouse Square, Queen Mary University of London, Charterhouse Square, London EC1M 6BQ, UK. ${ }^{3}$ Cancer Research Centre, Qatar Biomedical Research Institute, Qatar Foundation, Doha, Qatar. ${ }^{4}$ Centre for Experimental Cancer Medicine, Barts Cancer Institute, John Vane Science Centre, Charterhouse Square, Queen Mary University of London, Charterhouse Square, London EC1M 6BQ, UK. ${ }^{5}$ School of Biological Sciences, University of East Anglia, Norwich Research Park, Norwich NR4 7TJ, UK.

Received: 28 September 2016 Accepted: 2 March 2017 Published online: 23 March 2017

\section{References}

1. Burstein HJ, Polyak K, Wong JS, Lester SC, Kaelin CM. Ductal carcinoma in situ of the breast. N Engl J Med. 2004;350(14):1430-41.

2. Hannemann J, Velds A, Halfwerk JBG, Kreike B, Peterse JL, van de Vijver MJ. Classification of ductal carcinoma in situ by gene expression profiling. Breast Cancer Res. 2006;8:R61.

3. Deryugina El, Quigley JP. Matrix metalloproteinases and tumor metastasis. Cancer Metastasis Rev. 2006;25:9-34.

4. Jorgensen KJ, Gotzsche PC. Breast screening: fundamental errors in estimate of lives saved by screening. Br Med J. 2009;339.

5. Payne SJL, Bowen RL, Jones JL, Wells CA. Predictive markers in breast cancer-the present. Histopathology. 2008:52:82-90.

6. Ma XJ, Salunga R, Tuggle JT, Gaudet J, Enright E, McQuary P, Payette T, Pistone M, Stecker K, Zhang BM, et al. Gene expression profiles of human breast cancer progression. Proc Natl Acad Sci U S A. 2003;100(10):5974-9.

7. Clark SE, Warwick J, Carpenter R, Bowen RL, Duffy SW, Jones JL. Molecular subtyping of DCIS: heterogeneity of breast cancer reflected in pre-invasive disease. Br J Cancer. 2010;104:120-7.

8. Porter D, Lahti-Domenici J, Keshaviah A, Bae YK, Argani P, Marks J, Richardson A, Cooper A, Strausberg R, Riggins GJ, et al. Molecular markers in ductal carcinoma in situ of the breast. Mol Cancer Res. 2003;1 (5):362-75.

9. Allinen M, Beroukhim R, Cai L, Brennan C, Lahti-Domenici J, Huang H, Porter D, Hu M, Chin L, Richardson A, et al. Molecular characterization of the tumor microenvironment in breast cancer. Cancer Cell. 2004;6:17-32.

10. Chin K, de Solorzano CO, Knowles D, Jones A, Chou W, Rodriguez EG, Kuo W-L, Ljung B-M, Chew K, Myambo K, et al. In situ analyses of genome instability in breast cancer. Nat Genet. 2004;36:984-8.

11. Yao J, Weremowicz S, Feng B, Gentleman RC, Marks JR, Gelman R, Brennan C, Polyak K. Combined CDNA array comparative genomic hybridization and serial analysis of gene expression analysis of breast tumor progression. Cancer Res. 2006;66(8):4065-78.

12. Jones JL, Royall JE, Critchley DR, Walker RA. Modulation of myoepithelialassociated alpha6beta4 integrin in a breast cancer cell line alters invasive potential. Exp Cell Res. 1997;235(2):325-33.

13. Jones JL, Shaw JA, Pringle JH, Walker RA. Primary breast myoepithelial cells exert an invasion-suppressor effect on breast cancer cells via paracrine downregulation of MMP expression in fibroblasts and tumour cells. J Pathol. 2003; 201:562-72.

14. Barsky SH, Karlin NJ. Myoepithelial cells: autocrine and paracrine suppressors of breast cancer progression. J Mammary Gland Biol Neoplasia. 2005;10:249-60.

15. Sternlicht MD, Kedeshian P, Shao ZM, Safarians S, Barsky SH. The human myoepithelial cell is a natural tumor suppressor. Clin Cancer Res. 1997;3(11): 1949-58. 
16. Hu M, Yao J, Carroll DK, Weremowicz S, Chen H, Carrasco D, Richardson A, Violette S, Nikolskaya T, Nikolsky Y, et al. Regulation of in situ to invasive breast carcinoma transition. Cancer Cell. 2008;13:394-406.

17. Barsky S. Myoepithelial mRNA expression profiling reveals a common tumor-suppressor phenotype. Exp Mol Pathol. 2003;74:113-22.

18. Hu M, Yao J, Cai L, Bachman KE, van den Brûle F, Velculescu V, Polyak K Distinct epigenetic changes in the stromal cells of breast cancers. Nat Genet. 2005;37:899-905.

19. Polyak K, Kalluri R. The Role of the microenvironment in mammary gland development and cancer. Cold Spring Harb Perspect Biol. 2010;2:a003244.

20. Adriance MC, Inman JL, Petersen OW, Bissell MJ. Myoepithelial cells: good fences make good neighbors. Breast Cancer Res. 2005;7(5):190-7.

21. Van Lint P, Libert C. Matrix metalloproteinase-8: cleavage can be decisive. Cytokine Growth Factor Rev. 2006;17:217-23.

22. Gutiérrez-Fernández A, Fueyo A, Folgueras AR, Garabaya C, Pennington CJ, Pilgrim S, Edwards DR, Holliday DL, Jones JL, Span PN, et al. Matrix metalloproteinase-8 functions as a metastasis suppressor through modulation of tumor cell adhesion and invasion. Cancer Res. 2008;68:2755-63.

23. Bachmeier BE, lancu CM, Jochum M, Nerlich AG. Matrix metalloproteinases in cancer: comparison of known and novel aspects of their inhibition as a therapeutic approach. Expert Rev Anticancer Ther. 2005;5(1):149-63.

24. Kessenbrock K, Plaks V, Werb Z. Matrix metalloproteinases: regulators of the tumor microenvironment. Cell. 2010;141:52-67.

25. Lafleur MA, Handsley MM, Edwards DR. Metalloproteinases and their inhibitors in angiogenesis. Expert Rev Mol Med. 2004;5(23):1-39.

26. Palavalli LH, Prickett TD, Wunderlich JR, Wei X, Burrell AS, Porter-Gill P, Davis S, Wang C, Cronin JC, Agrawal NS, et al. Analysis of the matrix metalloproteinase family reveals that MMP8 is often mutated in melanoma. Nat Genet. 2009;41:518-20.

27. Allen MD, Thomas GJ, Clark S, Dawoud MM, Vallath S, Payne SJ, Gomm JJ, Dreger SA, Dickinson S, Edwards DR, et al. Altered microenvironment promotes progression of preinvasive breast cancer: myoepithelial expression of alphavbeta6 integrin in DCIS identifies high-risk patients and predicts recurrence. Clin Cancer Res. 2014;20(2):344-57.

28. Balbín M, Fueyo A, Tester AM, Pendás AM, Pitiot AS, Astudillo A, Overall CM, Shapiro SD, López-Otín C. Loss of collagenase-2 confers increased skin tumor susceptibility to male mice. Nat Genet. 2003;35:252-7.

29. Korpi JT, Kervinen $V$, Mäklin $H$, Väänänen $A$, Lahtinen $M$, Läärä E, Ristimäki $A$ Thomas G, Ylipalosaari M, Aström P, et al. Collagenase-2 (matrix metalloproteinase-8) plays a protective role in tongue cancer. $\mathrm{Br} J$ Cancer. 2008;98:766-75.

30. Gutiérrez-Fernández A, Inada M, Balbín M, Fueyo A, Pitiot AS, Astudillo A Hirose K, Hirata M, Shapiro SD, Noël A, et al. Increased inflammation delays wound healing in mice deficient in collagenase-2 (MMP-8). FASEB J. 2007; 21:2580-91.

31. Decock J, Long J-R, Laxton RC, Shu X-O, Hodgkinson C, Hendrickx W, Pearce EG, Gao Y-T, Pereira AC, Paridaens R, et al. Association of matrix metalloproteinase- 8 gene variation with breast cancer prognosis. Cancer Res. 2007;67:10214-21.

32. Decock J, Hendrickx W, Thirkettle S, Gutierrez-Fernandez A, Robinson SD, Edwards DR. Pleiotropic functions of the tumor- and metastasis-suppressing matrix metalloproteinase-8 in mammary cancer in MMTV-PyMT transgenic mice. Breast Cancer Res. 2015;17:38.

33. Tester AM, Cox JH, Connor AR, Starr AE, Dean RA, Puente XS, Lopez-Otin C, Overall CM. LPS responsiveness and neutrophil chemotaxis in vivo require PMN MMP-8 activity. PLoS One. 2007;2(3):e312.

34. Van Den Steen PE, Wuyts A, Husson SJ, Proost P, Van Damme J, Opdenakker G. Gelatinase B/MMP-9 and neutrophil collagenase/MMP-8 process the chemokines human GCP-2/CXCL6, ENA-78/CXCL5 and mouse GCP-2/LIX and modulate their physiological activities. Eur J Biochem. 2003;270(18): 3739-49.

35. Cox JH, Dean RA, Roberts $C R$, Overall CM. Matrix metalloproteinase processing of CXCL11/I-TAC results in loss of chemoattractant activity and altered glycosaminoglycan binding. J Biol Chem. 2008;283(28):19389-99.

36. Pellinen T, Rantala JK, Arjonen A, Mpindi JP, Kallioniemi O, Ivaska J. A functional genetic screen reveals new regulators of beta 1-integrin activity. J Cell Sci. 2012;125(3):649-61.

37. Quintero PA, Knolle MD, Cala LF, Zhuang Y, Owen CA. Matrix metalloproteinase-8 inactivates macrophage inflammatory protein-1 alpha to reduce acute lung inflammation and injury in mice. J Immunol. 2010; 184(3):1575-88.
38. Gomm JJ, Browne PJ, Coope RC, Liu QY, Buluwela L, Coombes RC. Isolation of pure populations of epithelial and myoepithelial cells from the normal human mammary-gland using immunomagnetic separation with Dynabeads. Anal Biochem. 1995;226(1):91-9.

39. Thirkettle S, Decock J, Arnold H, Pennington CJ, Jaworski DM, Edwards DR. Matrix metalloproteinase 8 (collagenase 2) induces the expression of interleukins 6 and 8 in breast cancer cells. J Biol Chem. 2013;288(23):16282-94.

40. Elbashir SM, Harborth J, Lendeckel W, Yalcin A, Weber K, Tuschl T. Duplexes of 21-nucleotide RNAs mediate RNA interference in cultured mammalian cells. Nature. 2001;411(6836):494-8.

41. Allen M, Mulligan K, Clark S, Hart I, Marshall JF, Jones JL. De novo expression of alpha(v)beta(6) integrin by myoepithelial cells in ductal carcinoma in situ may be an important marker of disease progression. Breast Cancer Res. 2008;10:S16-6.

42. Munger JS, Huang X, Kawakatsu H, Griffiths MJ, Dalton SL, Wu J, Pittet JF, Kaminski N, Garat C, Matthay MA, et al. The integrin alpha $\vee$ beta 6 binds and activates latent TGF beta 1: a mechanism for regulating pulmonary inflammation and fibrosis. Cell. 1999:96:319-28.

43. Bergstraesser LM, Srinivasan G, Jones JC, Stahl S, Weitzman SA. Expression of hemidesmosomes and component proteins is lost by invasive breast cancer cells. Am J Pathol. 1995;147(6):1823-39.

44. Mariotti A, Kedeshian PA, Dans M, Curatola AM, Gagnoux-Palacios L, Giancotti FG. EGF-R signaling through Fyn kinase disrupts the function of integrin alpha 6 beta 4 at hemidesmosomes: role in epithelial cell migration and carcinoma invasion. J Cell Biol. 2001;155(3):447-57.

45. de Pereda JM, Lillo MP, Sonnenberg A. Structural basis of the interaction between integrin alpha6beta4 and plectin at the hemidesmosomes. EMBO J. 2009;28(8):1180-90.

46. Chioni AM, Fraser SP, Pani F, Foran P, Wilkin GP, Diss JK, Djamgoz MB. A novel polyclonal antibody specific for the $\mathrm{Na}(\mathrm{v}) 1.5$ voltage-gated $\mathrm{Na}(+)$ channel 'neonatal' splice form. J Neurosci Methods. 2005;147(2):88-98.

47. Pal-Ghosh S, Blanco T, Tadvalkar G, Pajoohesh-Ganji A, Parthasarathy A, Zieske JD, Stepp MA. MMP9 cleavage of the beta4 integrin ectodomain leads to recurrent epithelial erosions in mice. J Cell Sci. 2011;124(Pt 15):2666-75.

48. Jones JL. Overdiagnosis and overtreatment of breast cancer: progression of ductal carcinoma in situ: the pathological perspective. Breast Cancer Res. 2006;8:204.

49. Virnig BA, Tuttle TM, Shamliyan T, Kane RL. Ductal carcinoma in situ of the breast: a systematic review of incidence, treatment, and outcomes. J Natl Cancer Inst. 2010;102(3):170-8.

50. Castro NP, Osório CA, Torres C, Bastos EP, Mourão-Neto M, Soares F, Brentani HP, Carraro DM. Evidence that molecular changes in cells occur before morphological alterations during the progression of breast ductal carcinoma. Breast Cancer Res. 2008;10:R87.

51. Ma X-J, Dahiya S, Richardson E, Erlander M, Sgroi DC. Gene expression profiling of the tumor microenvironment during breast cancer progression. Breast Cancer Res. 2009;11:R7.

52. Gudjonsson T, Ronnov-Jessen L, Villadsen R, Rank F, Bissell MJ, Petersen OW. Normal and tumor-derived myoepithelial cells differ in their ability to interact with luminal breast epithelial cells for polarity and basement membrane deposition. J Cell Sci. 2002;115(1):39-50.

53. Bissell MJ, Bilder D. Polarity determination in breast tissue: desmosomal adhesion, myoepithelial cells, and laminin 1. Breast Cancer Res. 2003;5:117-9.

54. Bissell MJ, Kenny PA, Radisky DC. Microenvironmental regulators of tissue structure and function also regulate tumor induction and progression: the role of extracellular matrix and its degrading enzymes. Cold Spring Harb Symp Quant Biol. 2005;70:343-56.

55. Zhang X, Hashemi SS, Yousefi M, Ni J, Wang Q, Gao L, Gong P, Gao C, Sheng J, Mason J, et al. Aberrant c-erbB2 expression in cell clusters overlying focally disrupted breast myoepithelial cell layers: a trigger or sign for emergence of more aggressive cell clones? Int J Biol Sci. 2008;4(5):259-69.

56. Blackburn JS, Brinckerhoff CE. Wild-type versus mutant MMP-8 in melanoma: 'when you come to a fork in the road, take it'. Pigment Cell Melanoma Res. 2009;22(3):248-50.

57. Moilanen M, Pirilä E, Grénman R, Sorsa T, Salo T. Expression and regulation of collagenase-2 (MMP-8) in head and neck squamous cell carcinomas. J Pathol. 2002;197:72-81.

58. López-Otín C, Palavalli LH, Samuels Y. Protective roles of matrix metalloproteinases: from mouse models to human cancer. Cell Cycle. 2009:8:3657-62.

59. Dejonckheere E, Vandenbroucke RE, Libert C. Matrix metalloproteinase8 has a central role in inflammatory disorders and cancer progression. Cytokine Growth Factor Rev. 2011;22:73-81. 
60. Man Y-G, Sang Q-XA. The significance of focal myoepithelial cell layer disruptions in human breast tumor invasion: a paradigm shift from the "protease-centered" hypothesis. Exp Cell Res. 2004;301:103-18.

61. Zhan L, Rosenberg A, Bergami KC, Yu M, Xuan Z, Jaffe AB, Allred C, Muthuswamy SK. Deregulation of scribble promotes mammary tumorigenesis and reveals a role for cell polarity in carcinoma. Cell. 2008;135(5):865-78.

62. Muschler J, Streuli CH. Cell-matrix interactions in mammary gland development and breast cancer. Cold Spring Harb Perspect Biol. 2010;2(10):a003202.

63. Rabinovitz I, Toker A, Mercurio AM. Protein kinase C-dependent mobilization of the alpha 6 beta 4 integrin from hemidesmosomes and its association with actin-rich cell protrusions drive the chemotactic migration of carcinoma cells. J Cell Biol. 1999;146(5):1147-60.

64. Ozawa T, Tsuruta D, Jones JC, Ishii M, Ikeda K, Harada T, Aoyama Y, Kawada A, Kobayashi H. Dynamic relationship of focal contacts and hemidesmosome protein complexes in live cells. J Invest Dermatol. 2010;130(6):1624-35.

65. Germain EC, Santos TM, Rabinovitz I. Phosphorylation of a novel site on the beta 4 integrin at the trailing edge of migrating cells promotes hemidesmosome disassembly. Mol Biol Cell. 2009;20(1):56-67.

66. Chioni AM, Grose R. FGFR1 cleavage and nuclear translocation regulates breast cancer cell behavior. J Cell Biol. 2012;197(6):801-17.

67. Polyak K, Haviv I, Campbell IG. Co-evolution of tumor cells and their microenvironment. Trends Genet. 2009;25(1):30-8.

68. Astrom P, Pirila E, Lithovius R, Heikkola H, Korpi JT, Hernandez M, Sorsa T, Salo T. Matrix metalloproteinase-8 regulates transforming growth factorbeta1 levels in mouse tongue wounds and fibroblasts in vitro. Exp Cell Res. 2014:328(1):217-27.

69. Soria-Valles C, Gutierrez-Fernandez A, Guiu M, Mari B, Fueyo A, Gomis RR, Lopez-Otin C. The anti-metastatic activity of collagenase-2 in breast cancer cells is mediated by a signaling pathway involving decorin and miR-21. Oncogene. 2014;33(23):3054-63.

70. Francis A, Thomas J, Fallowfield L, Wallis M, Bartlett JM, Brookes C, Roberts T, Pirrie S, Gaunt C, Young J, et al. Addressing overtreatment of screen detected DCIS; the LORIS trial. Eur J Cancer. 2015:51(16):2296-303.

\section{Submit your next manuscript to BioMed Central and we will help you at every step:}

- We accept pre-submission inquiries

- Our selector tool helps you to find the most relevant journal

- We provide round the clock customer support

- Convenient online submission

- Thorough peer review

- Inclusion in PubMed and all major indexing services

- Maximum visibility for your research

Submit your manuscript at www.biomedcentral.com/submit

\section{(O) BioMed Central}

